\title{
Three-Dimensional Distribution of Turbulent Mixing in the South China Sea*
}

\author{
QINGXUAN YANG AND WEI ZHAO \\ Physical Oceanography Laboratory, Ocean University of China, Qingdao, China \\ XINFENG LIANG \\ Department of Earth, Atmospheric and Planetary Sciences, Massachusetts Institute of Technology, Cambridge, Massachusetts \\ JIWEI TIAN \\ Physical Oceanography Laboratory, Ocean University of China, Qingdao, China
}

(Manuscript received 27 October 2014, in final form 4 December 2015)

\begin{abstract}
A three-dimensional distribution of turbulent mixing in the South China Sea (SCS) is obtained for the first time, using the Gregg-Henyey-Polzin parameterization and hydrographic observations from 2005 to 2012. Results indicate that turbulent mixing generally increases with depth in the SCS, reaching the order of $10^{-2} \mathrm{~m}^{2} \mathrm{~s}^{-1}$ at depth. In the horizontal direction, turbulence is more active in the northern SCS than in the south and is more active in the east than the west. Two mixing "hotspots" are identified in the bottom water of the Luzon Strait and Zhongsha Island Chain area, where diapycnal diffusivity values are around $3 \times$ $10^{-2} \mathrm{~m}^{2} \mathrm{~s}^{-1}$. Potential mechanisms responsible for these spatial patterns are discussed, which include internal tide, bottom bathymetry, and near-inertial energy.
\end{abstract}

\section{Introduction}

The South China Sea (SCS) is the largest marginal sea of the northwestern Pacific, with a wide range of bathymetric features and oceanographic processes. There are deep basins, steep continental slopes, and broad continental shelves in the SCS. In the deep basin, the existence of energetic internal tides, generated near the Luzon Strait, has been confirmed by both observations (Tian et al. 2009; Klymak et al. 2011) and numerical simulations (Niwa and Hibiya 2004; Jan et al. 2007). In the northern SCS, high-frequency nonlinear internal waves with large amplitude and high velocity, such as solitons, are widely spread. The SCS is considered one of the most active regions in the ocean for such waves (Zhao et al. 2004; Alford et al. 2010). When

\footnotetext{
* Supplemental information related to this paper is available at the Journals Online website: http://dx.doi.org/10.1175/JPO-D-14-0220.s1.

Corresponding author address: Jiwei Tian, 238 Songling Road, Qingdao, 266100, China.

E-mail: tianjw@ouc.edu.cn
}

encountering prominent topography, such as steep slope and the Dongsha Island in the northern SCS, the northwestward-propagating internal tides evolved into internal solitary waves (Lien et al. 2005). Most energy of these nonlinear internal waves eventually dissipates to supply turbulent mixing over the broad shelf region in the northern SCS (Lien et al. 2005; Chang et al. 2006). Extensive research has been conducted during the Asian Sea International Acoustics Experiment (ASIAE), which has significantly improved our understanding on these waves and their associated processes (e.g., Duda et al. 2004; Ramp et al. 2004).

The SCS is considered a hotspot of turbulent mixing (St. Laurent 2008; Tian et al. 2009). Turbulent mixing in the SCS drives water exchange between the SCS and the Pacific (e.g., Qu et al. 2006; Zhou et al. 2014). However, studies of the turbulent mixing in the SCS are patchy in space due to limited data. Based on a finescale parameterization, Tian et al. (2009) examined turbulent mixing distribution along a section from the SCS to the Pacific and found the mixing beneath $1000 \mathrm{~m}$ in the SCS was two orders larger than in the Pacific. Through McLane Moored Profiler measurements at a mooring site over the northern SCS slope, Klymak 


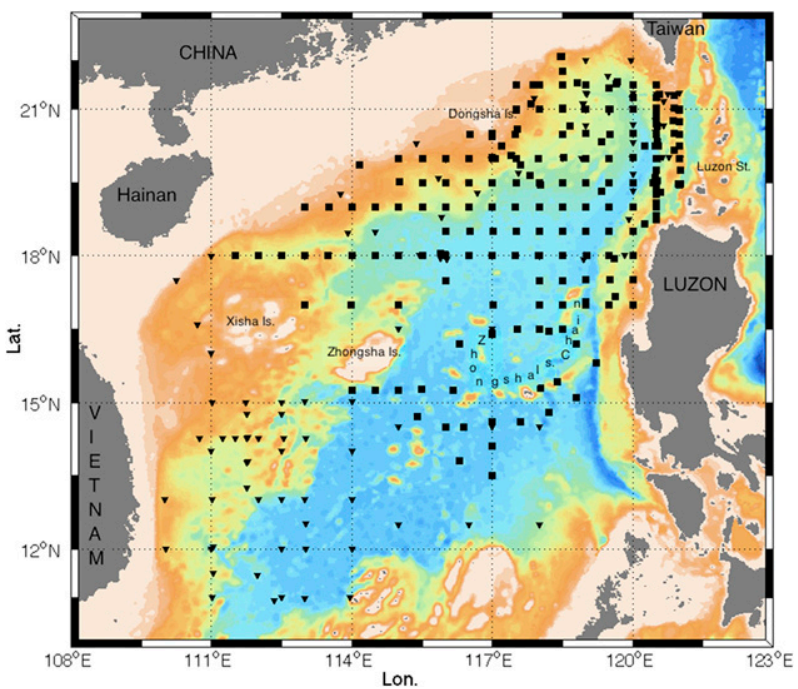

FIG. 1. Bathymetry of the South China Sea. Solid squares indicate the stations where both CTD and LADCP measurements are available, and triangles mark the stations with CTD measurements only.

et al. (2011) observed large overturning events exceeding $200 \mathrm{~m}$ in thickness, which were associated with turbulence dissipation as high as $10^{-5} \mathrm{~W} \mathrm{~kg}^{-1}$. Using the Thorpe-scale method, Alford et al. (2011) and Buijsman et al. (2012) revealed elevated diffusivity in the deep water of the Luzon Strait, which is considered as being modulated by internal tides. A few direct measurements from microstructure profiler are available. Over the shallow water in the shelf break region northeast of the Dongsha Island, St. Laurent (2008) found high dissipation as large as $10^{-6} \mathrm{~W} \mathrm{~kg}^{-1}$. Lozovatsky et al. (2013) examined the spatial structure and temporal variability of turbulent dissipation in limited areas of the northern SCS. Yang et al. (2014) suggested that the turbulence in the SCS is more energetic over the shelf, being an order larger than that over the slope. They also examined the temporal variability of turbulent mixing and found that internal tides and Kuroshio intrusion are the main factors driving the mixing variability over shelf and slope, respectively.

There is no doubt that these studies have improved our knowledge about the turbulent mixing in the northern SCS. However, these studies based on spatially patchy measurements during different periods have failed to provide a detailed picture of turbulent mixing in the whole SCS. Specifically, there is no report on mixing in the southern SCS to our knowledge. Because of the lack of understanding of the turbulent mixing variability in the whole SCS, the products from numerical simulations based on a simple parameterization of eddy diffusivity should be treated with caution.
TABLE 1. Information on the data used in this study.

\begin{tabular}{|c|c|c|}
\hline Year & Data & Month \\
\hline 2005 & $\mathrm{LADCP}+\mathrm{CTD}$ & October \\
\hline 2006 & CTD & September + November + December \\
\hline 2007 & $\mathrm{LADCP}+\mathrm{CTD}$ & July + August \\
\hline 2008 & $\begin{array}{l}\text { CTD } \\
\text { LADCP + CTD } \\
\text { CTD }\end{array}$ & $\begin{array}{l}\text { July }+ \text { August }+ \text { September } \\
\text { April }+ \text { August } \\
\text { October }\end{array}$ \\
\hline 2009 & $\mathrm{LADCP}+\mathrm{CTD}$ & March + April \\
\hline 2010 & $\begin{array}{l}\text { LADCP + CTD } \\
\text { CTD }\end{array}$ & $\begin{array}{l}\text { March } \\
\text { May }+ \text { August }+ \text { November }\end{array}$ \\
\hline 2011 & $\begin{array}{l}\text { LADCP + CTD } \\
\text { CTD }\end{array}$ & $\begin{array}{l}\text { April } \\
\text { August }+ \text { September }\end{array}$ \\
\hline 2012 & $\mathrm{LADCP}+\mathrm{CTD}$ & April \\
\hline
\end{tabular}

The goal of this study is to present a three-dimensional (3D) structure of turbulent mixing in the whole SCS, based on hydrographic measurements. To our knowledge, it is the first time that such an attempt has been made. The paper is organized as follows. A brief description of the data and methods is presented in section 2 . A 3D structure of turbulent mixing in the SCS is given in section 3. Associated mechanisms and a summary are provided in section 4 .

\section{Data and methods}

\section{a. Data}

There were a total of 335 stations (477 casts) in the SCS from 2005 to 2012, which covered the whole SCS (Fig. 1). The months with data coverage in each year varied from March to December, and the specific data period for each field experiment is shown in Table 1. At each station, measurements of temperature, salinity, and pressure were obtained by the conductivitytemperature-depth (CTD) system using SBE 911plus, SBE 917plus, or SBE 25 (Sea-Bird Electronics). SBE 911/917 and SBE 25 CTD worked at frequencies of 24 and $8 \mathrm{~Hz}$, respectively. With the pre- and postcruise calibrations, the accuracies of the CTD sensors are $0.001 \mathrm{psu}$ for salinity and $0.001^{\circ} \mathrm{C}$ for temperature. In this study, only the downcast data are used, and the data shallower than $10 \mathrm{~m}$ are discarded because the CTD sensors were not stable before reaching $10 \mathrm{~m}$. At 240 stations (319 casts), velocity profiles were simultaneously measured by a $300-\mathrm{kHz}$ WorkHorse Sentinel lowered acoustic Doppler current profiler (LADCP, Teledyne RD Instruments). The vertical bin size was set to $10 \mathrm{~m}$, the number of layers was set to 15 , and the sampling frequency was set to $1 \mathrm{~Hz}$. The LADCP collected relative velocities, namely, current velocities with respect to the instrument itself, with an estimated 
uncertainty of $1 \mathrm{~cm} \mathrm{~s}^{-1}$ (based on the datasheet of Teledyne RD Instruments). The method we used to process the LADCP data is the inverse method, using the software from Andreas M. Thurnherr's release, version IX_10 (Thurnherr 2010). Besides these finescale observations, microscale sampling was carried out at four stations using a turbulent ocean microstructure acquisition profiler (TurboMAP-L, JFE Advantech Co. Ltd.). The TurboMAP system was equipped with two shear probes, which sampled shear at $512 \mathrm{~Hz}$. The noise level of TurboMAP for measuring dissipation rate is $10^{-10} \mathrm{~W} \mathrm{~kg}^{-1}$.

\section{b. Gregg-Henyey-Polzin parameterization}

The Gregg-Henyey-Polzin (GHP) scaling based on the internal wave-wave interaction theory (Gregg et al. 2003) is employed to estimate turbulent kinetic energy dissipation rate $\varepsilon$. This scaling can be expressed in terms of shear and/or strain as follows:

$$
\begin{aligned}
\varepsilon & =\varepsilon_{0} \frac{N^{2}}{N_{0}^{2}} \frac{\left\langle V_{z}^{2}\right\rangle^{2}}{\mathrm{GM}_{z}\left\langle V_{z}^{2}\right\rangle^{2}} h_{1}\left(R_{\omega}\right) j\left(\frac{f}{N}\right), \\
\varepsilon & =\varepsilon_{0} \frac{N^{2}}{N_{0}^{2}} \frac{\left\langle\xi_{z}^{2}\right\rangle^{2}}{\mathrm{GM}\left\langle\xi_{z}^{2}\right\rangle^{2}} h_{2}\left(R_{\omega}\right) j\left(\frac{f}{N}\right), \\
h_{1}\left(R_{\omega}\right) & =\frac{3\left(R_{\omega}+1\right)}{2 \sqrt{2} R_{\omega} \sqrt{R_{\omega}-1}}, \\
h_{2}\left(R_{\omega}\right) & =\frac{1}{6 \sqrt{2}} \frac{R_{\omega}\left(R_{\omega}+1\right)}{\sqrt{R_{\omega}-1}}, \text { and } \\
j(f / N) & =\frac{f \operatorname{arccosh}(N / f)}{f_{30} \operatorname{arccosh}\left(N / f_{30}\right)},
\end{aligned}
$$

where $\varepsilon_{0}=6.73 \times 10^{-10} \mathrm{~W} \mathrm{~kg}^{-1}$, and $f$ and $N$ are the Coriolis and buoyancy frequencies, respectively (Kunze et al. 2006). The term $R_{\omega}$ is the shear-to-strain variance ratio, defined as $R_{\omega}=\left\langle V_{z}^{2}\right\rangle /\left(\overline{N^{2}}\left\langle\xi_{z}^{2}\right\rangle\right)$, where $\left\langle V_{z}^{2}\right\rangle$ and $\left\langle\xi_{z}^{2}\right\rangle$ represent the finescale internal wave shear and strain variance inferred from observations, respectively. In (1) and (2), ${ }_{\mathrm{GM}}\left\langle V_{z}^{2}\right\rangle$ and ${ }_{\mathrm{GM}}\left\langle\xi_{z}^{2}\right\rangle$ are the shear and strain variances inferred from the Garrett and Munk (GM) spectrum (Garrett and Munk 1972, 1975). In the GM model, an open-ocean internal wave field is constructed at a fixed buoyancy frequency of $N_{0}$ $\left(5.2 \times 10^{-3} \mathrm{rad} \mathrm{s}^{-1}\right)$ at the latitude of $30^{\circ}$. Here, parameterization (1) is used for the stations where both LADCP and CTD observations are available, and parameterization (2) is used with a fixed $R_{\omega}$ value at the other stations where only CTD observations are available. Given that $R_{\omega}$ varies from region to region (e.g., Waterman et al. 2013), we examine its distribution at the stations where both LADCP and CTD data
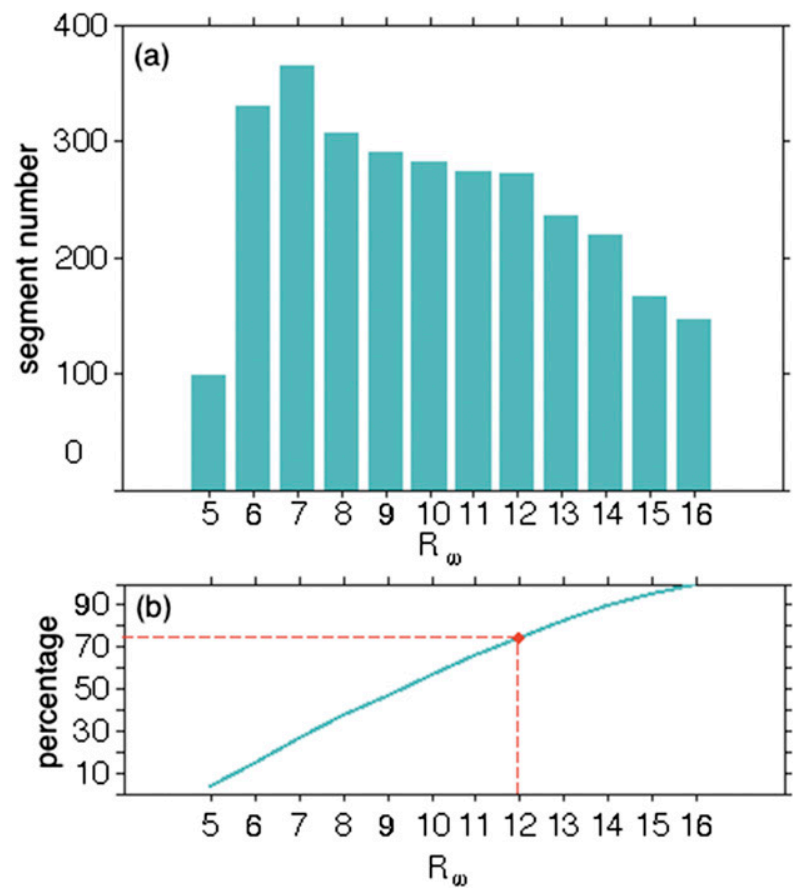

FIG. 2. (a) Histogram of $R_{\omega}$ and (b) its cumulative percentage.

are available (Fig. 2). Altogether, 2987 segments were taken into consideration. The histogram indicates a peak at $R_{\omega}=7$, and the number of segments with $R_{\omega}$ ranging from 5 to 12 accounts for $74 \%$ of the total number. Meanwhile, the $h_{2}\left(R_{\omega}\right)$ value at $R_{\omega}=12$ is 5.5, about 2 times the value at $R_{\omega}=7$, which is 2.7. As a result, using $R_{\omega}=7$ will lead to uncertainty in turbulent diffusivity by a factor of $3-4$, at most. Based on this, a constant value $\left(R_{\omega}=7\right)$ is used for simplicity when employing parameterization (2).

To quantify shear and strain variances, profiles of shear and strain with a vertical bin of $10 \mathrm{~m}$ were divided into half-overlapping 320-m-long segments, starting from the bottom. The term $\left\langle V_{z}^{2}\right\rangle$ was obtained by integrating corrected shear spectra $S_{V_{z}}(k) S_{c 1}$ from the minimum wavenumber $k_{1}$ to the maximum wavenumber $k_{2}$ using $\left\langle V_{z}^{2}\right\rangle=\int_{k_{1}}^{k_{2}} S_{V_{z}}(k) S_{c 1} d k$. The shear spectral correction

$$
S_{c 1}=\frac{1}{\operatorname{sinc}^{4}\left(\frac{k_{z} \Delta h_{1}}{2 \pi}\right) \operatorname{sinc}^{4}\left(\frac{k_{z} \Delta h_{2}}{2 \pi}\right)}
$$

takes into account smoothing associated with range averaging, depth binning, superensemble preaveraging, and instrument tilting (Thurnherr 2012), where $\Delta h_{1}$ represents the vertical bin size set for LADCP deployment, and $\Delta h_{2}$ represents the vertical depth interval for the shear-strain profile. The term $k_{1}$ is defined as the 

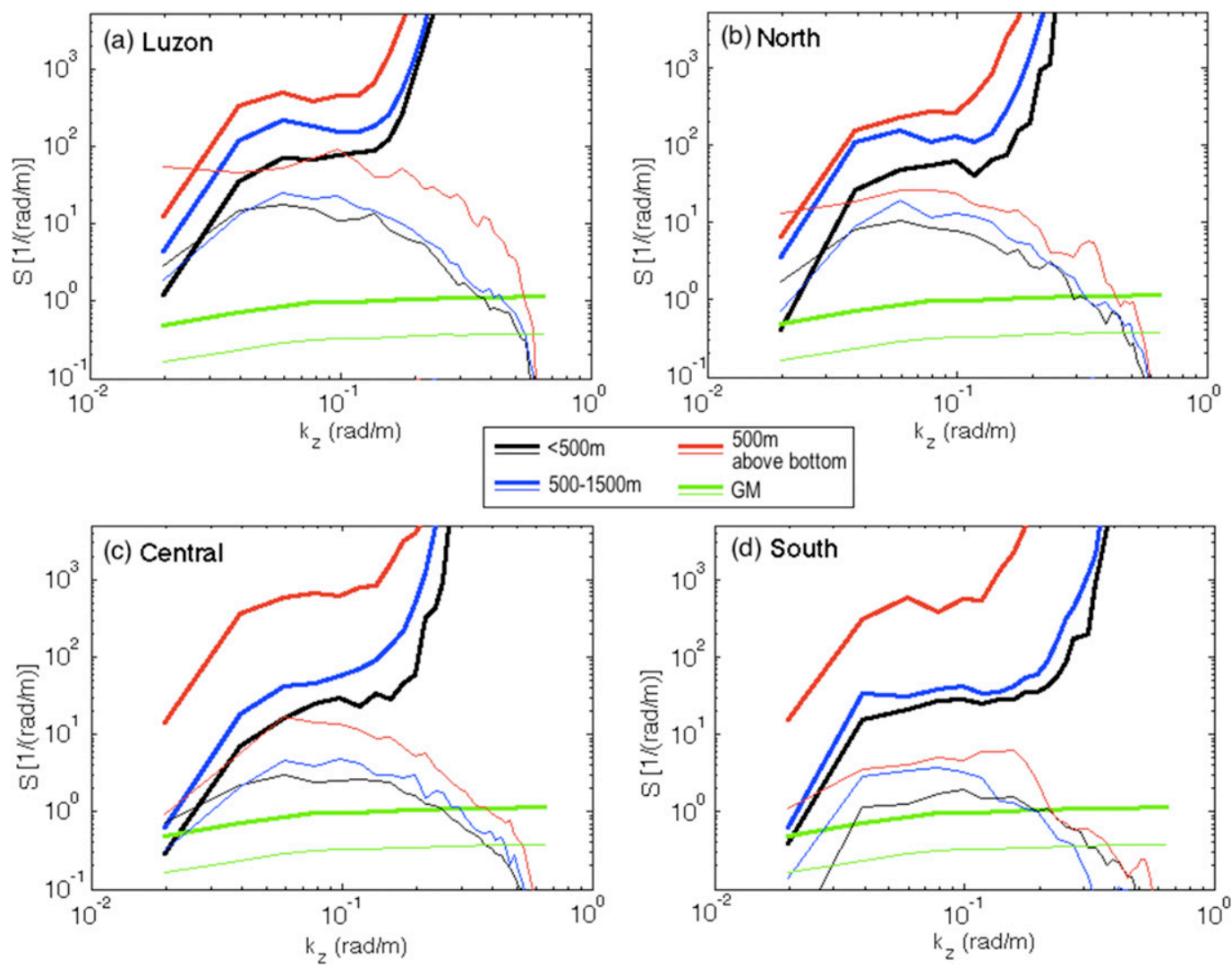

FIG. 3. Area-averaged spectra of vertical shear (thick curves) and strain (thin curves) in the (a) Luzon Strait, (b) the northern SCS, (c) the central SCS, and (d) the southern SCS, along with the GM model spectra (green curves). The four regions are indicated in Fig. 8f. The black, blue, and red indicate depth ranges of $<500 \mathrm{~m}, 500$ $1500 \mathrm{~m}$, and $500 \mathrm{~m}$ above the bottom, respectively.

reciprocal of the record length being analyzed; $k_{2}$ is determined as a wavenumber at which the ratio of measured shear spectrum to shear noise spectrum is 3 (Naveira Garabato et al. 2004), which mostly stays around $0.1 \mathrm{rad} \mathrm{m}^{-1}$ (Fig. 3). In this study, we model the shear noise spectrum as a blue spectrum, the value of which is proportional to squared wavenumber. The root-mean-square (RMS) noise level of velocity measured by a $300-\mathrm{kHz}$ LADCP is approximately $0.032 / \sqrt{n_{\text {ping }}} \mathrm{m} \mathrm{s}^{-1}$ under optimal conditions for a large number of scatters, where $n_{\text {ping }}=120$ is the number of pings typically averaged into each depth bin (Polzin et al. 2002). As a result, the instrument shear noise spectrum can be expressed as

$$
S_{\text {noise }}=\frac{0.032^{2}}{120} \frac{k_{z}^{2}}{N_{2}} S_{c 1}
$$

Strain is computed using $\xi_{z}=\left(\theta_{z}-\bar{\theta}_{z}\right) / \bar{\theta}_{z}$, where $\theta_{z}$ is the potential temperature gradient and $\bar{\theta}_{z}$ is its mean value based on a quadratic fit to each potential temperature gradient segment. Strain can also be estimated based on stratification, namely, $\xi_{z}=\left(N^{2}-\overline{N^{2}}\right) / \overline{N^{2}}$. Here, we use the former to avoid bringing noise from the conductivity measurements into the strain derivation, although the strain results inferred from the two forms differ only slightly. The term $\left\langle\xi_{z}^{2}\right\rangle$ is obtained by integrating corrected strain spectrum $S_{\xi_{z}}(k) S_{c 2}$ over the same wavenumber band as calculating $\left\langle V_{z}^{2}\right\rangle$ using $\left\langle\xi_{z}^{2}\right\rangle=\int_{k_{1}}^{k_{2}} S_{\xi_{z}}(k) S_{c 2} d k$. Here, the strain spectral correction due to first differencing inherent in the gradient is $S_{c 2}=1 / \operatorname{sinc}^{2}\left[\left(k_{z} \Delta h_{2}\right) / 2 \pi\right]$. When using parameterization (2), the upper integration limit of strain variance is determined by $\int_{k_{1}}^{k_{2}} S_{\xi_{z}} d k \leq 0.1$ (Kunze et al. 2006), since velocity data are not available.

The averaged shear and strain spectra are binned into four areas (the Luzon Strait, the northern, central, and southern SCS), associated with their corresponding GM spectra (Fig. 3). A striking feature is that the internal wave energy is elevated in the near-bottom layer in all four areas, which indicates enhanced turbulent mixing in the deep SCS. In the vertical direction, the 

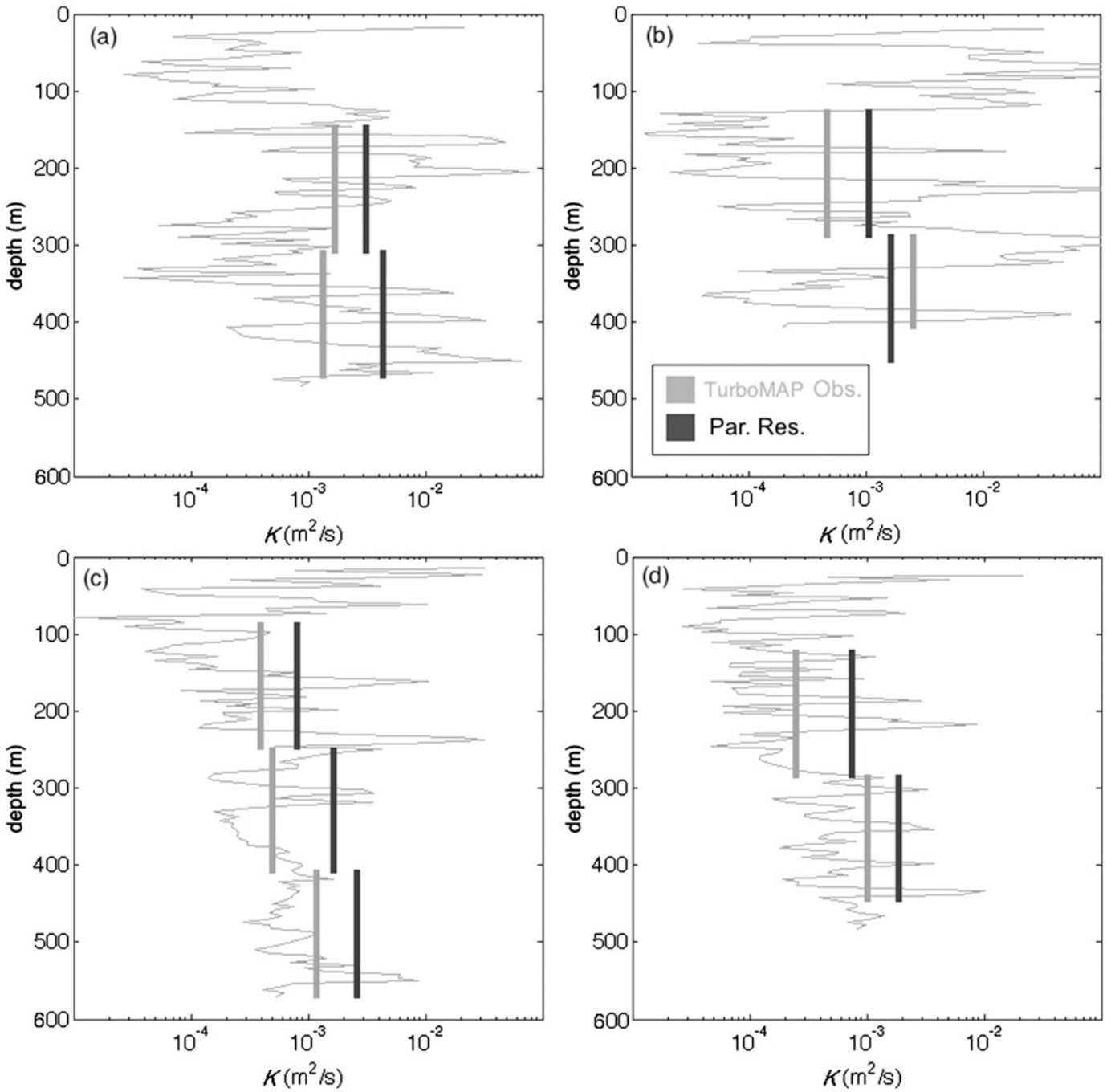

FIG. 4. TurboMAP observations and GHP parameterization results at four stations along $120^{\circ} 30^{\prime} \mathrm{E}: 19^{\circ} 40^{\prime} \mathrm{N}$, $20^{\circ} 20^{\prime} \mathrm{N}, 20^{\circ} 40^{\prime} \mathrm{N}$, and $21^{\circ} 00^{\prime} \mathrm{N}$. The thin gray curves are the TurboMAP measurements with high spatial resolution, the gray vertical lines are depth-averaged TurboMAP results (arithmetic mean), and the black vertical lines are parameterization results.

energy level shows a clear enhancement from shallow water to the bottom in these areas, which indicates increased mixing with depth. The GHP scaling was initially developed for the open ocean, and its applicability in the marginal sea should be further examined due to its potential limitations (Polzin et al. 2014). The comparison of the two sets of results based on the GHP parameterization and microscale measurements by TurboMAP shows similar overall trends (Fig. 4). Although mostly both are in the same order of magnitude, there are quantitative differences between TurboMAP observations and results from the parameterization, by a factor of $2-4$, among individual profiles at different depths. The parameterization has a slight tendency to overestimate the dissipation rate compared to the
TurboMAP measurement; this tendency may be caused by applying the GHP parameterization in the SCS (as mentioned above about its applicability in the marginal sea). The fact that two different methods give similar turbulence levels suggests that the GHP parameterization results obtained in this study are reliable.

\section{c. Thorpe-scale method}

Thanks to the well-established relationship between the Ozmidov scale and the Thorpe scale $\left(L_{T}\right.$; Dillon 1982), the dissipation rate $\varepsilon$ can be related to $L_{T}$ as follows:

$$
\varepsilon=0.64 L_{T}^{2} N^{3},
$$




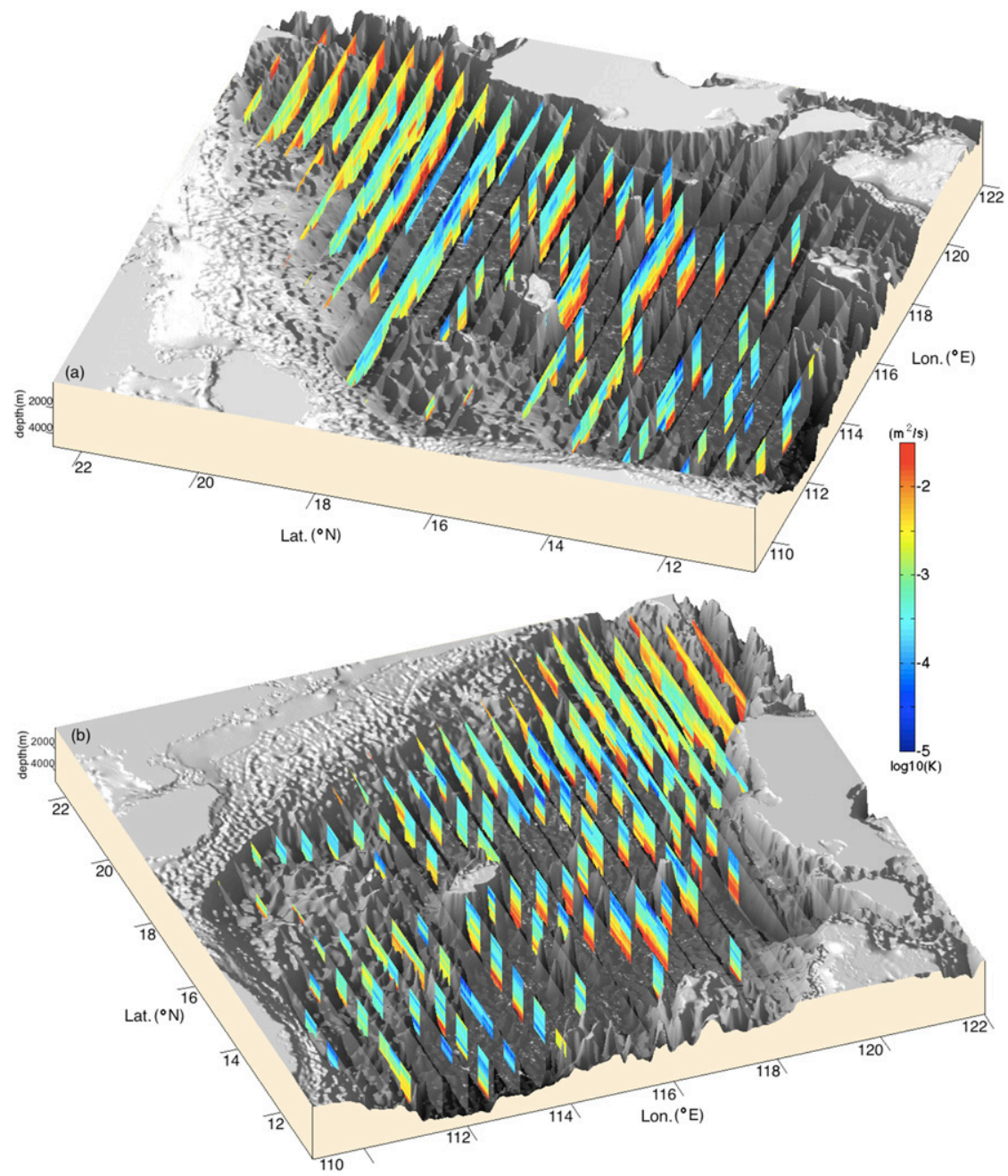

FIG. 5. Spatial structure of diapycnal diffusivity $\left(\mathrm{m}^{2} \mathrm{~s}^{-1} ;\right.$ logarithmic scale) in a 3D view; (a) the zonal sections and (b) the meridional sections.

where $L_{T}$ can be calculated as the RMS displacement of a parcel, and the buoyancy frequency $N$ is evaluated using the gradient of the reordered density profile. Here, the displacement is defined as the depth difference between a measured density profile and its reordered version (Finnigan et al. 2002). The run length and water mass tests proposed by Galbraith and Kelley (1996) are employed to reject spurious overturns (see appendix B for more detail). The disadvantage of the Thorpe-scale method is that overturns could not be easily detected in a shallow layer if there exists a strong stratification. Therefore, there may be turbulence even though no overturns are detected in the water column. In this study, we use this method to estimate diffusivity in the deeper water column only to avoid an underestimation of $\varepsilon$ due to overturns in the upper layer not being fully resolved. To derive diapycnal diffusivity $K$ from the GHP and Thorpe-scale inferred $\varepsilon$, the most common model of Osborn (1980) is employed, namely, $K=\Gamma\left(\varepsilon / N^{2}\right)$, where mixing efficiency $\Gamma$ is set to 0.2 .

\section{Results}

\section{a. GHP scaling results}

To show the spatial distribution more clearly, the profiles of dissipation rate and buoyancy frequency at all stations are first binned into a $1 / 4^{\circ} \times 1 / 4^{\circ}$ grid and then the averaged diffusivity profile at each bin is derived. The 3D structure of diapycnal diffusivity in the SCS is shown in Fig. 5. The zonal sections (Fig. 5a) illustrate that diffusivity decreases from the northern SCS to the southern SCS, except for some high diffusivity in the Zhongsha Island Chain area. The meridional sections (Fig. 5b) show that diffusivity weakens significantly from the eastern SCS to the western SCS. The 3D structure 

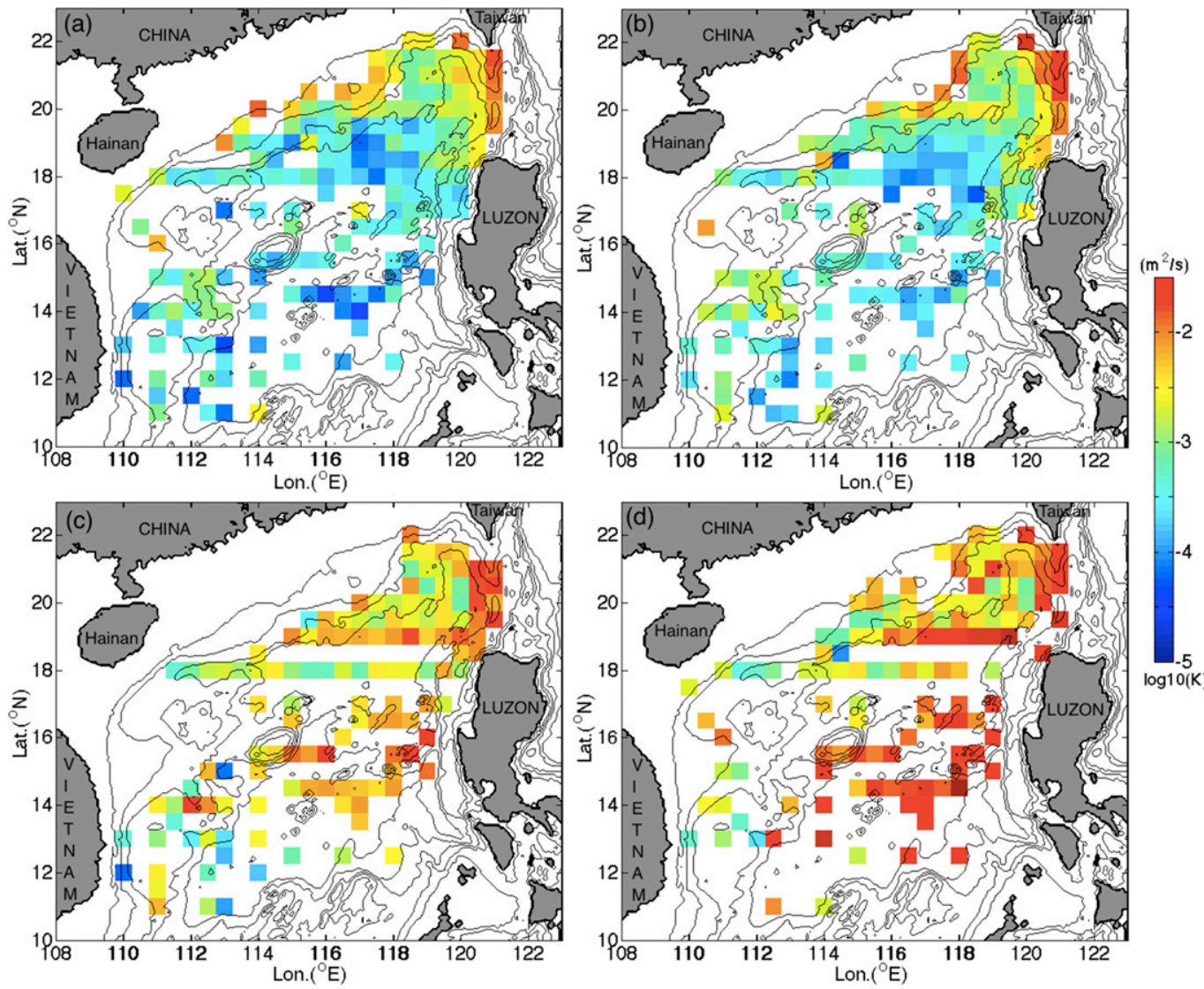

FIG. 6. Maps of depth-averaged diffusivity $\left(\mathrm{m}^{2} \mathrm{~s}^{-1}\right.$; logarithmic scale) for the (a) upper layer $(0-500 \mathrm{~m})$, (b) intermediate layer $(500-1500 \mathrm{~m})$, (c) deep layer $(>1500 \mathrm{~m})$, and $(\mathrm{d})$ near-bottom layer $(500 \mathrm{~m}$ above the bottom).

viewed from both zonal and meridional sections shows an obvious feature that the turbulence is enhanced in the deep SCS and in the whole water column of the Luzon Strait. Figure 6 shows the depth-averaged diffusivity in the upper layer $(<500 \mathrm{~m})$, intermediate layer $(500$ $1500 \mathrm{~m})$, deep layer $(>1500 \mathrm{~m})$, and near-bottom layer ( $500 \mathrm{~m}$ above the bottom). In the upper layer, remarkably high diffusivity exists in the Luzon Strait, which is as high as $10^{-2} \mathrm{~m}^{2} \mathrm{~s}^{-1}$. Another area with elevated mixing is at and north of $20^{\circ} \mathrm{N}$ (and west of $120^{\circ} \mathrm{E}$ ), where the magnitude of diffusivity is $10^{-3} \mathrm{~m}^{2} \mathrm{~s}{ }^{-1}$. In contrast, the diffusivity south of $20^{\circ} \mathrm{N}$ reduces to $10^{-4} \mathrm{~m}^{2} \mathrm{~s}^{-1}$ or even to $10^{-5} \mathrm{~m}^{2} \mathrm{~s}^{-1}$. A similar spatial pattern exists in the intermediate layer. However, the diffusivity in the intermediate layer is generally larger than that in the upper layer. In the deep layer, diffusivity is approximately one order larger than that in the intermediate layer. The Luzon Strait is characterized by enhanced mixing, with diffusivity exceeding $10^{-2} \mathrm{~m}^{2} \mathrm{~s}^{-1}$. The diffusivity values north of $20^{\circ} \mathrm{N}$ and south of $20^{\circ} \mathrm{N}$ are almost at the same level in the deep layer, different from the spatial patterns in the upper and intermediate layers. In the near-bottom layer, diffusivity is significantly elevated in the Zhongsha Island Chain area and the Luzon Strait, with values of $10^{-2} \mathrm{~m}^{2} \mathrm{~s}^{-1}$ or larger. The heightened mixing along $19^{\circ} \mathrm{N}$ in the near-bottom layer should be examined further because we have no explanation for its presence.

The averaged diffusivity values in different layers along zonal and meridional directions are shown in Fig. 7. In the zonal direction, the variations in the upper and intermediate layers have similar trends, with values of $10^{-4} \mathrm{~m}^{2} \mathrm{~s}^{-1}$ from $110^{\circ}$ to $117^{\circ} \mathrm{E}$ and increasing sharply to $10^{-2} \mathrm{~m}^{2} \mathrm{~s}^{-1}$ when reaching the Luzon Strait. The diffusivity values in both deep and near-bottom layers show similar variability, which increases gradually from $10^{-3}$ to $10^{-2} \mathrm{~m}^{2} \mathrm{~s}^{-1}$ from the west to the east. The wholedepth-averaged diffusivity mostly stays at the level of $10^{-3} \mathrm{~m}^{2} \mathrm{~s}^{-1}$ with a rising trend toward the east, except for some extreme values of $10^{-4}$ and $10^{-2} \mathrm{~m}^{2} \mathrm{~s}^{-1}$ at the westernmost and easternmost ends, respectively. Just as the variability in the zonal direction, the variations in the upper and intermediate layers, or those in the deep and near-bottom layers, are similar in the meridional 

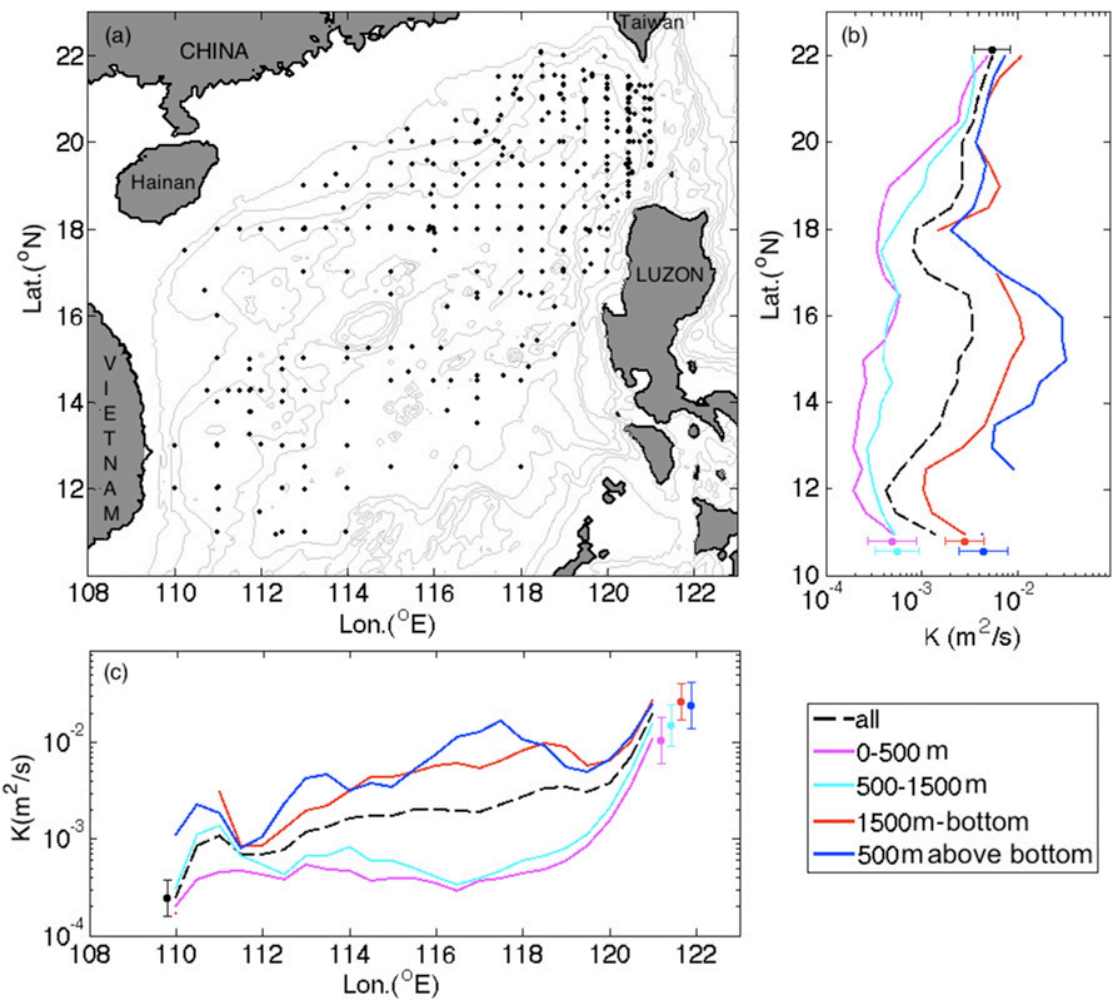

FIG. 7. (a) The SCS map and station locations. Depth-averaged diffusivity $\left(\mathrm{m}^{2} \mathrm{~s}^{-1}\right)$ for different layers in the (b) meridional and (c) zonal directions. The error bars are given in (b) and (c), which indicate the uncertainty of standard deviation.

direction. The diffusivity in the upper and intermediate layers is weakened by one order from $10^{-3} \mathrm{~m}^{2} \mathrm{~s}^{-1}$ in the north to $10^{-4} \mathrm{~m}^{2} \mathrm{~s}^{-1}$ in the south. In the deep and nearbottom layers, significantly intensified turbulence activity exists between $13^{\circ}$ and $17^{\circ} \mathrm{N}$, with enhanced diffusivity exceeding $10^{-2} \mathrm{~m}^{2} \mathrm{~s}^{-1}$ in the near-bottom layer. When averaged in the whole water column, diffusivity displays a decreasing trend from the north to the south. Four regions, namely, the Luzon Strait and the northern, central, and southern SCS, are selected to further examine vertical distributions of area-averaged dissipation, buoyancy frequency, and diffusivity derived from these two mean variables in the SCS (Fig. 8). A common feature of the four regions is that diffusivity increases with depth. A striking diffusivity profile is found in the Luzon Strait, with values ranging from $5 \times$ $10^{-3}$ to $4 \times 10^{-2} \mathrm{~m}^{2} \mathrm{~s}^{-1}$, much larger than those in the other three areas. Such large diffusivity in the Luzon Strait was reported before. For example, Alford et al. (2011) showed diffusivity as large as $3 \times 10^{-2} \mathrm{~m}^{2} \mathrm{~s}^{-1}$ around 2000-m depth in the Luzon Strait, comparable with our value of $1 \times 10^{-2} \mathrm{~m}^{2} \mathrm{~s}^{-1}$ at the same depth. However, our estimated diffusivity in the upper layer is higher than that of Alford et al. (2011), which may be caused by seasonal variability because the observations of Alford et al. (2011) were from summer, while our measurements include two winters. The associated dissipation rate is about $2 \times 10^{-8} \mathrm{~W} \mathrm{~kg}^{-1}$ below $2000 \mathrm{~m}$ in the Luzon Strait, also exceeding the levels in the other regions. Among the other three regions, diffusivity at a depth shallower than $2500 \mathrm{~m}$ is the strongest in the northern SCS and is the weakest in the southern SCS until reaching $3100 \mathrm{~m}$. Deeper than $2500 \mathrm{~m}$, diffusivity in the central SCS becomes the largest; below $3100 \mathrm{~m}$, the values in the northern SCS become the smallest. The dissipation rates below $2000 \mathrm{~m}$ mostly stay around $10^{-9} \mathrm{~W} \mathrm{~kg}^{-1}$. The basin-averaged diffusivity profile reveals that the mixing level is larger than $10^{-3} \mathrm{~m}^{2} \mathrm{~s}^{-1}$ below $1400 \mathrm{~m}$ and even reaches $10^{-2} \mathrm{~m}^{2} \mathrm{~s}^{-1}$ below $3300 \mathrm{~m}$. This suggests enhanced turbulent mixing in the deep SCS, which supports the finding of Tian et al. (2009).

\section{b. Thorpe-scale results}

An example of overturn with a depth range from 790 to $890 \mathrm{~m}$ is identified at $21.11^{\circ} \mathrm{N}, 117.84^{\circ} \mathrm{E}$ in the northern SCS, where the water depth is $1000 \mathrm{~m} ; 12$ profiles of LADCP/CTD were collected during $34 \mathrm{~h}$ (Figs. 9a,b). Potential temperature and salinity in the water column 

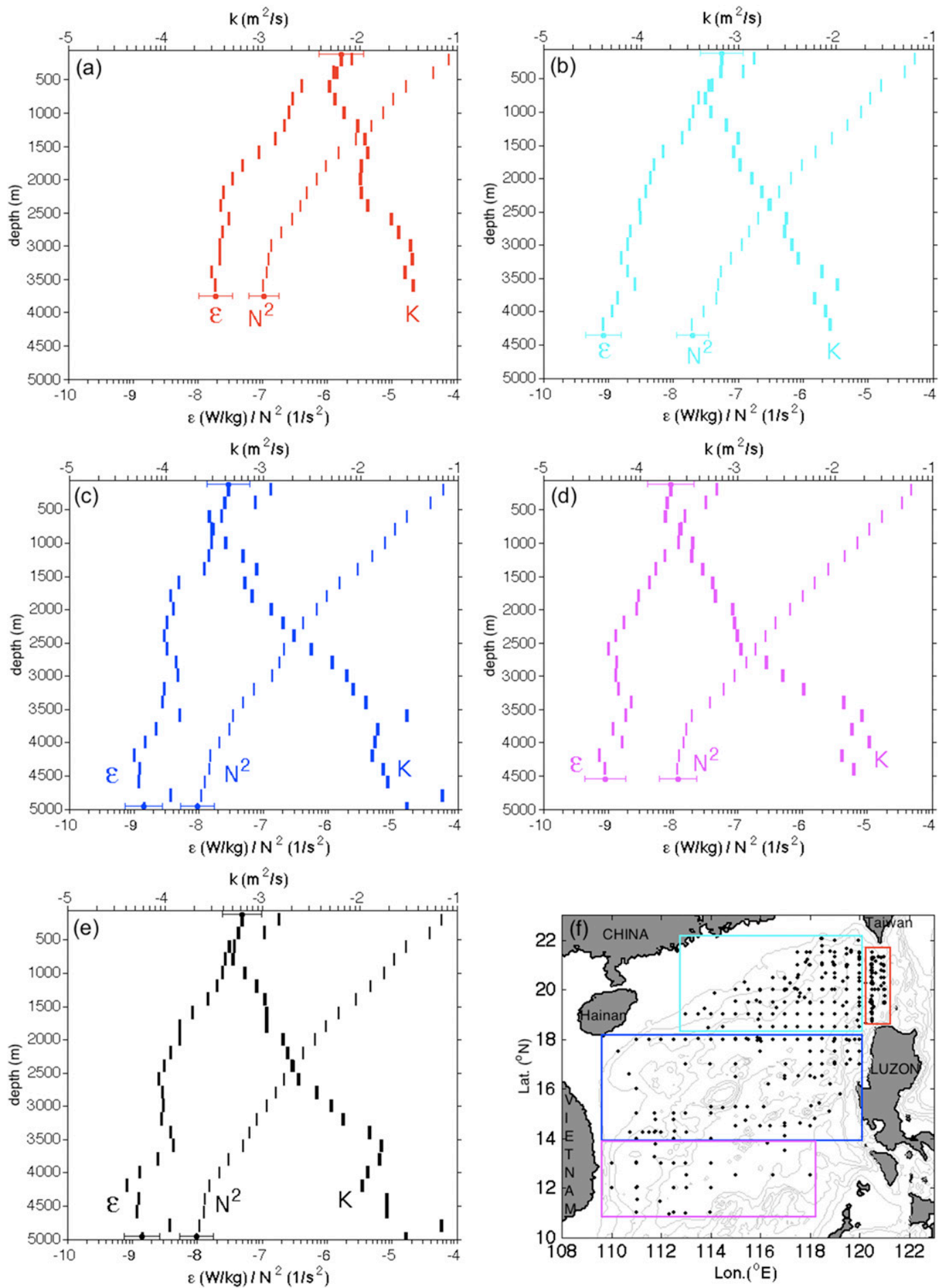

FIG. 8. (a)-(d) Area-averaged profiles of dissipation rate $\varepsilon\left(\mathrm{W} \mathrm{kg}^{-1}\right)$, buoyancy frequency $N^{2}\left(\mathrm{~s}^{-2}\right)$ and diffusivity $K\left(\mathrm{~m}^{2} \mathrm{~s}^{-1}\right)$ in the four regions as indicated in (f). Note the colors in (a)-(d) are the same as the colors used for boxes in (f). (e) The averaged profiles over the whole SCS. We use the logarithmic scale for the $x$ axis in (a)-(e), with error bars to indicate the uncertainty of standard deviation. In (a)-(e) the top $x$-axis is for $K$ and the bottom $x$-axis is for $\varepsilon$ and $N^{2}$. 

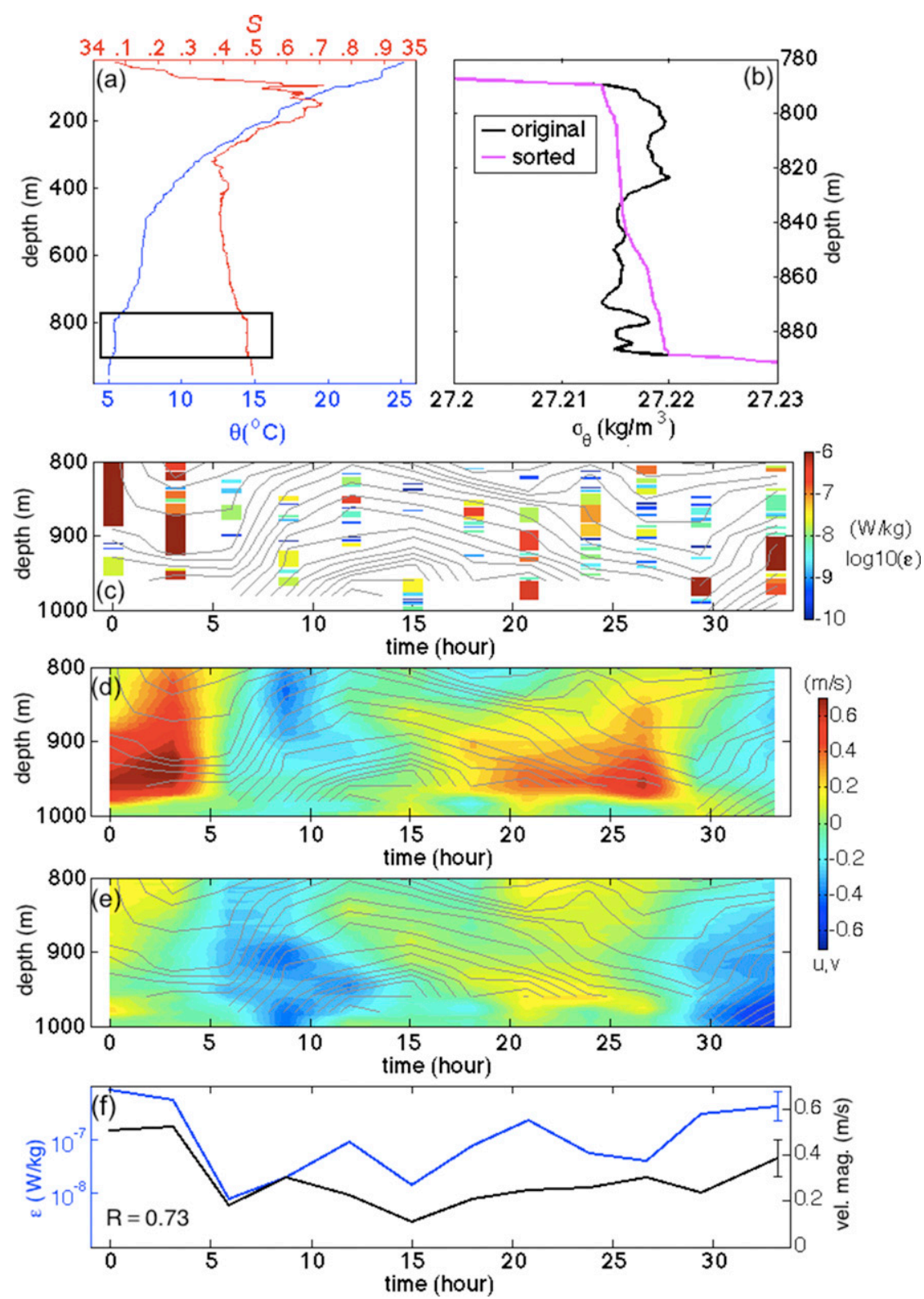

FIG. 9. (a) Vertical profiles of potential temperature and salinity in the northern SCS. (b) An overturn detected from the original and sorted potential density profiles in the depth range indicated by the black box in (a). The time series of dissipation rate $\left(\mathrm{W} \mathrm{kg}^{-1}\right)$ based on the (c) Thorpe-scale estimate and the (d) zonal and (e) meridional components of horizontal velocity $\left(\mathrm{m} \mathrm{s}^{-1}\right.$ ), with isopycnal curves (gray) superimposed. (f) The depth-averaged dissipation rate and velocity magnitude, where the error bars indicate the uncertainty of standard deviation. The data used to construct this figure are from repeatedly occupied stations of LADCP/CTD. A logarithmic scale is used for diffusivity in (c).

were nearly uniform in the vertical. The original and sorted potential density profiles show a remarkable overturn with denser water overlying lighter water. At a similar location, Klymak et al. (2011) found even larger overturning events with a thickness exceeding $200 \mathrm{~m}$, twice that shown in Figs. 9a and 9b. The time series of inferred diffusivity at this location are further examined (Figs. 9c-e) using Thorpe-scale estimates as well as zonal and meridional velocities. The frequency of the signals was predominantly diurnal. Turbulent mixing was elevated when the tidal current reached its maximum, and a correlation coefficient between them is 0.73 

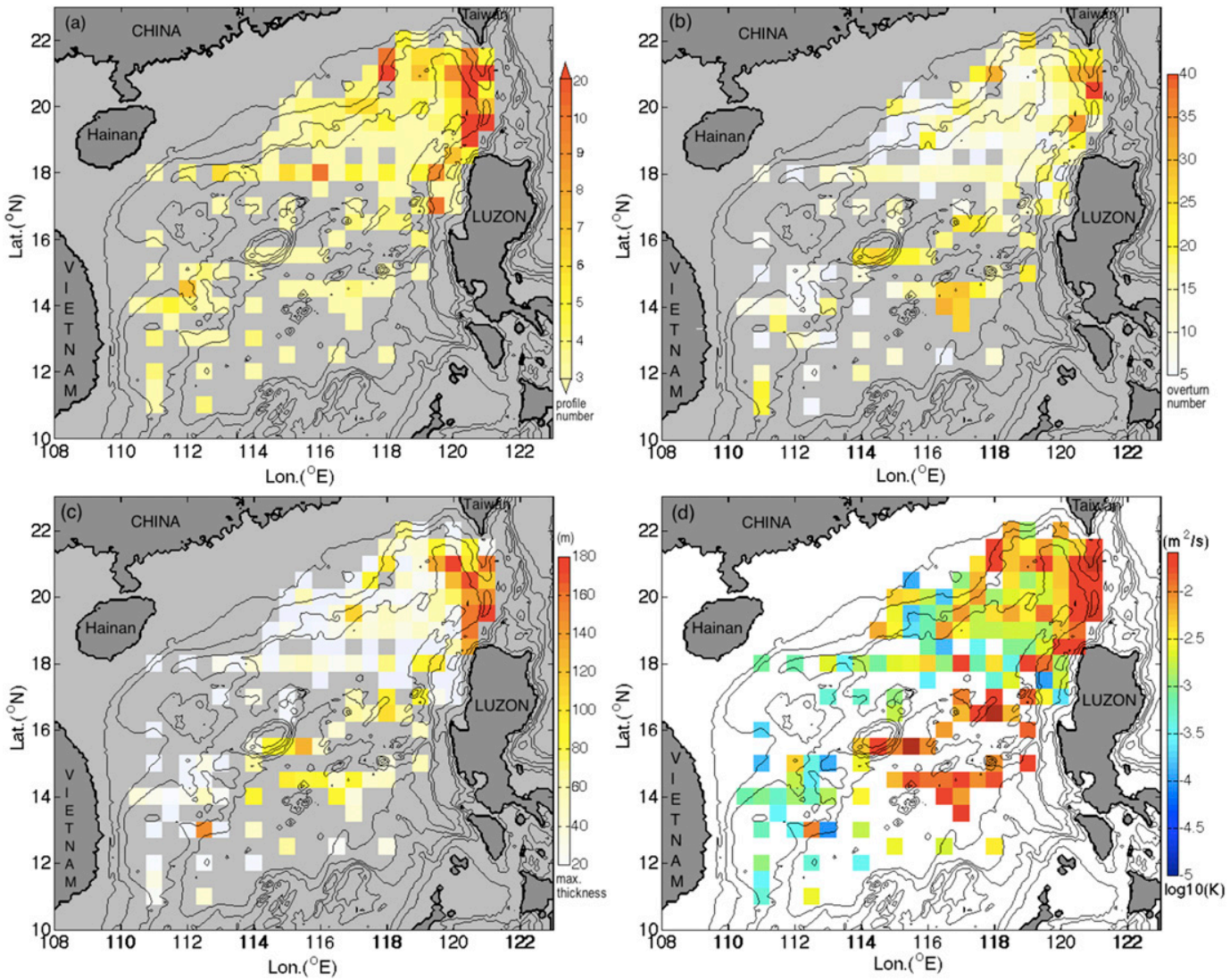

FIG. 10. Maps of (a) the number of profiles used in averaging, (b) mean number of overturns, (c) the maximum overturn thickness $(\mathrm{m})$, and (d) the depth-averaged diffusivity inferred from the Thorpe-scale estimate $\left(\mathrm{m}^{2} \mathrm{~s}^{-1}\right)$ for the near-bottom layer. A logarithmic scale is used for diffusivity in (d).

(Fig. 9f). Similar results were reported by Alford and Pinkel (2000) and by Levine and Boyd (2006) near California and Hawaii, respectively.

The number of profiles used in averaging, overturn number, and the maximum thickness of the overturns at each grid in the near-bottom layer of the SCS are given in Figs. 10a, 10b, and 10c, respectively. The overturn number varied spatially, mostly ranging from 10 to 40 . A large number of overturns occurred in the Luzon Strait and its adjacent northern SCS, as well as in the Zhongsha Island Chain, with the number exceeding 15 . The maximum thickness of the detected overturns was mostly between 20 and $180 \mathrm{~m}$. There were remarkable overturns with thicknesses between 140 and $180 \mathrm{~m}$ in the Luzon Strait, where Alford et al. (2011) reported a striking overturn with thickness larger than $500 \mathrm{~m}$. Some large overturns with thicknesses of $80 \mathrm{~m}$ or larger exist in the northern SCS, and in the Zhongsha Island Chain as well. Compared with the neighboring area of the Pacific, where the thickness of the largest overturn was mostly smaller than $20 \mathrm{~m}$ (Yang et al. 2014), the overturns in the SCS were rather energetic. These results support the conclusion of Tian et al. (2009) that the turbulent mixing in the SCS is much stronger than that in the Pacific. The spatial pattern of diffusivity in the near-bottom layer is reconstructed from Thorpe-scale estimates (Fig. 10d). The result is the averaged diffusivity based on many overturns (Fig. 10b) with substantial size (Fig. 10c), not just from one individual profile. It shows enhanced mixing in the SCS deep basin. Two areas with significantly elevated diffusivity are the Luzon Strait and the Zhongsha Island Chain, with maximum values of $10^{-2} \mathrm{~m}^{2} \mathrm{~s}^{-1}$ or larger. This structure agrees well with the GHP scaling results; however, there is a discrepancy in magnitude by a factor of 2-3 between these two methods (Fig. 11). Examining variations of the two results with buoyancy frequency, the correlation between them reaches 0.72 . The discrepancies mainly occurred in the low stratification regions, where both GHP parameterization and Thorpe-scale method have relatively high noise. Nevertheless, the diffusivity estimates based on GHP scaling and Thorpe-scale estimates yield similar spatial patterns, which add to our confidence in the diffusivity map obtained in this study. 


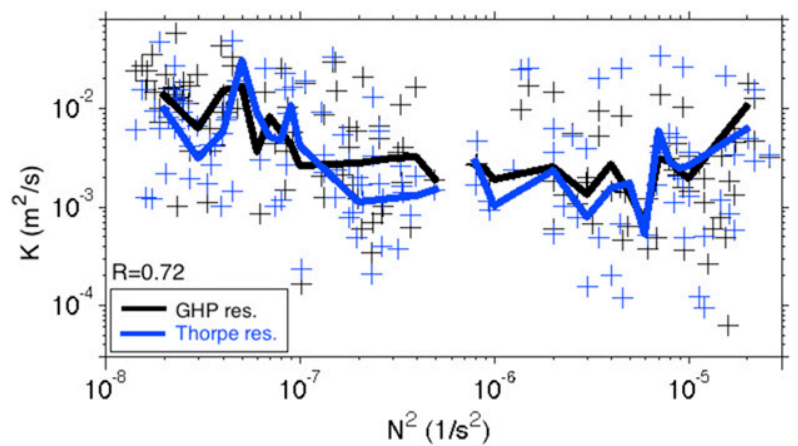

FIG. 11. Distribution of averaged diffusivity for the near-bottom layer with respect to buoyancy frequency. The black curve indicates the GHP scaling results and the blue indicates the Thorpescale estimates. The correlation coefficient between these two curves is 0.72 . The values based on the GHP scaling and Thorpescale methods before averaging are indicated by black and blue pluses, respectively. Logarithmic scales are used for both $x$ and $y$ axis.

\section{Discussion and summary}

\section{a. The Luzon Strait}

The Luzon Strait is an area with vigorous turbulence in almost the entire water column. Prominent topographic features include two parallel north-southoriented ridges, interacting effectively with normally incident barotropic tides. This promotes energy conversion from barotropic tides to internal tides. Niwa and Hibiya (2004) revealed that $14-\mathrm{GW} \mathrm{M}_{2}$ barotropic energy flux (one-quarter of the total) is converted to $\mathrm{M}_{2}$ internal tides, and about half, or $6.6 \mathrm{GW}$, is dissipated to furnish local turbulent dissipation before radiating away from the Luzon Strait. Buijsman et al. (2012) suggested high-mode turbulent lee waves account for the elevated dissipation in the deep water of the Luzon Strait; they also pointed out the key role of the double ridges in leewave generation. Yang et al. (2014) noted that the shear instability associated with Kuroshio intrusion plays a nonnegligible role in strengthening the turbulent mixing in the Luzon Strait. These factors may lead to the remarkably high diffusivity in the Luzon Strait inferred in this study.

\section{b. The northern South China Sea}

There are some potential candidates in the northern SCS that can contribute to the turbulent mixing in the region, such as internal solitary waves, internal tides, and near-inertial internal waves. The northern SCS has a high occurrence area of internal solitary waves, which mainly exist north of $20^{\circ} \mathrm{N}$, especially around the Dongsha Island (Zhao et al. 2004). The solitary waves in the deep basin are associated with relatively small shear

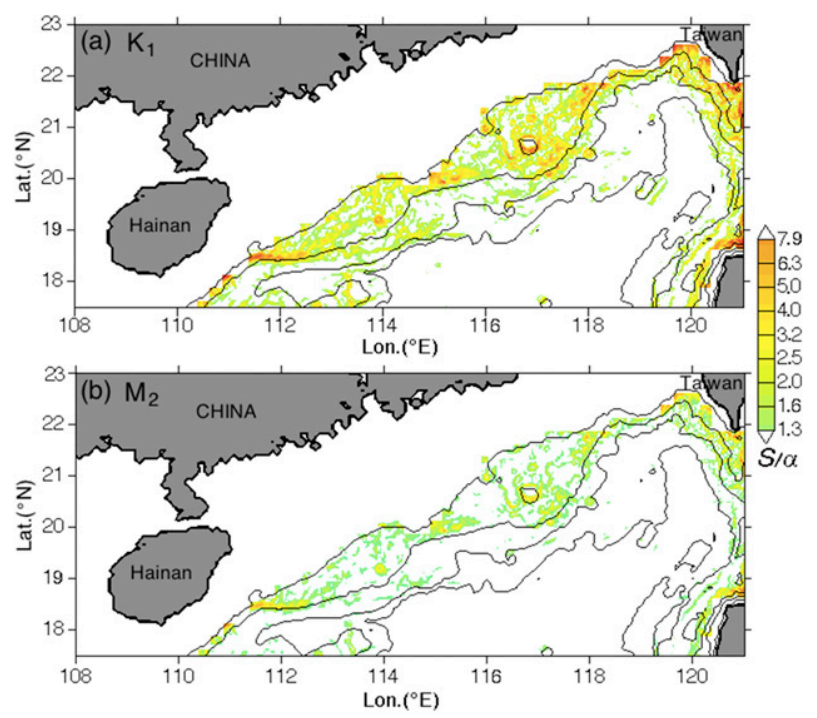

FIG. 12. Area of supercritical bathymetry for internal tides (a) $\mathrm{K}_{1}$ and (b) $\mathrm{M}_{2}$ in the northern SCS. The colors indicate the slope criticality, with only the supercritical area shown. The bathymetry data are from the Smith-Sandwell database (Smith and Sandwell 1997), and stratification is calculated using the annual temperature and salinity data of the WOA13.

and exhibit weak turbulence (e.g., Klymak et al. 2006). They can, however, trigger mixing events on the base of preexisting background shears (Pinkel 2000). When propagating west to the shelf and slope of the northern SCS, solitary waves become dissipative, exhibit strong shears, and generate turbulence due to shear instability (e.g., $\mathrm{Xu}$ et al. 2012). This is consistent with the diffusivity pattern in Fig. 6a, in which the values around the Dongsha Island are 3-4 times larger than those east of the island in the upper layer. Based on the mooring observations in this area, Lien et al. $(2005,2014)$ revealed a dissipation rate as high as $1.5 \times 10^{-4} \mathrm{~W} \mathrm{~kg}^{-1}$ caused by solitary waves. Compared to propagating solitary waves, the contribution of locally generated internal waves is small. For example, Klymak et al. (2011) found that the generation of local internal waves is less than one-tenth of the incoming waves.

The energy of internal tides generated from the Luzon Strait and entering the northern SCS is also an important source to sustain the high mixing away from the shelf. The slope in the northern SCS is supercritical with respect to both diurnal and semidiurnal internal tides, although the supercritical region for the semidiurnal tides is narrower than that for the diurnal tides (Fig. 12). Here, the slope criticality $S / \alpha$ is defined as the ratio of local topographic slope, to the energy propagation slope of a radiated tidal beam $\alpha=\sqrt{\left(\omega^{2}-f^{2}\right) /\left(N^{2}-\omega^{2}\right)}$. In this calculation, the bathymetry data are from the 

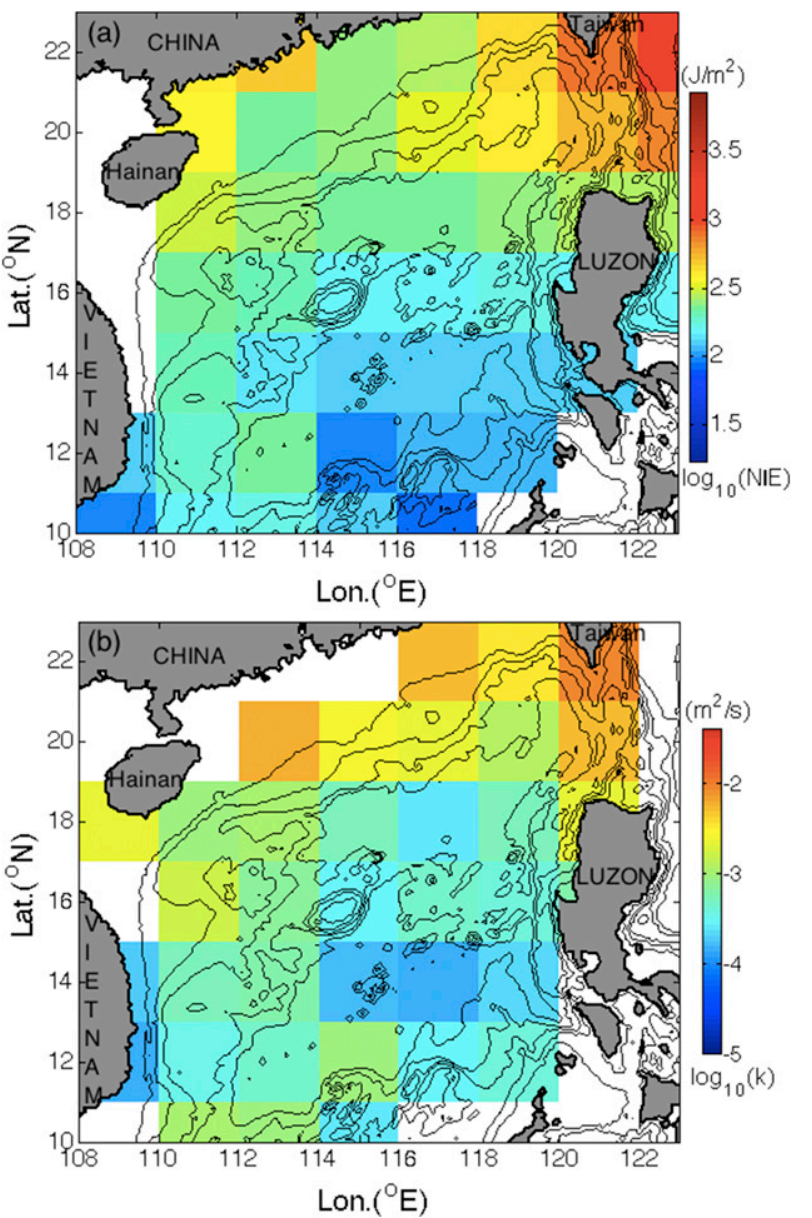

FIG. 13. Maps of (a) near-inertial energy $\left(\mathrm{J} \mathrm{m}^{-2}\right)$ and (b) depthaveraged diffusivity $\left(\mathrm{m}^{2} \mathrm{~s}^{-1}\right)$ for the upper layer. Logarithmic scales are used for energy and diffusivity. (a) is similar to Fig. 1c of Chaigneau et al. (2008); we redraw it using the same dataset as Chaigneau et al. (2008), which is available online (at http://ctoh. legos.obs-mip.fr/applications/mesoscale/climatology-of-near-inertialcurrents)

Smith-Sandwell database (Smith and Sandwell 1997); the stratification data are obtained from the climatological dataset of the World Ocean Atlas 2013 (WOA13; available online at https://www.nodc.noaa. gov/cgi-bin/OC5/woa13/woa13.pl); $\omega$ and $f$ are tidal frequency and Coriolis frequency, respectively. Because of this kind of criticality, the slope in the northern SCS acts as a barrier, that is, most incoming energy is reflected back, with the higher vertical modes becoming gradually dominant. As a result, the energy is trapped in the deep basin of the northern SCS and eventually dissipates to furnish the mixing there. Klymak et al. (2011) estimated that one-third of the incoming diurnal tidal energy is reflected into the SCS basin and used to facilitate turbulent mixing. Consistent with the above-mentioned processes, Tian et al.
(2009) made an estimate based on the assumption that 8-GW internal tide energy are dissipated in the SCS and deduced a diffusivity value of $10^{-3} \mathrm{~m}^{2} \mathrm{~s}^{-1}$ in the deep water of the SCS.

The ocean can obtain energy from wind by generating near-inertial internal waves, which enter the surface mixed layer, propagate downward, and dissipate in the interior eventually, as noted by Alford et al. (2012). Comparison between the climatological near-inertial energy level (Fig. 13a) and the diffusivity in the upper layer (Fig. 13b) shows similar patterns. The near-inertial energy in the northern SCS, say at $20^{\circ} \mathrm{N}$, is notably higher than that in the southern SCS, say at $14^{\circ} \mathrm{N}$. The energy difference between the two latitudes is almost one order in magnitude. This agrees well with the diffusivity map in the upper layer, that is, the higher the near-inertial energy, the higher the diffusivity, implying the contribution from wind to the diffusivity in the upper layer. In summary, these three kinds of internal waves (internal solitary waves, internal tides, and near-inertial internal waves) are important factors driving the highlevel mixing in the northern SCS.

\section{c. The Zhongsha Island Chain}

Figure 14 compares zonally averaged diffusivity, bottom roughness, shear variance, and strain variance in the near-bottom layer of the central SCS. Bottom roughness is defined as the bathymetry variance calculated in bins of $1 / 4^{\circ} \times 1 / 4^{\circ}$, which is considered a suitable spatial scale for internal tide generation by St. Laurent and Garrett (2002). The zonally averaged diffusivity peaks at about $5 \times 10^{-2} \mathrm{~m}^{2} \mathrm{~s}^{-1}$ around $15.5^{\circ} \mathrm{N}$, where a series of small ridges are present along the east-west direction. Bathymetry roughness reaches its maximum of $5 \times 10^{5} \mathrm{~m}^{2}$ across the ridges, where $V_{z}^{2}$ and $N^{2} \xi_{z}^{2}$ are simultaneously elevated to $2.5 \times 10^{-5}$ and $3.5 \times$ $10^{-5} \mathrm{~s}^{-2}$, respectively. This structure is similar to that over the Hawaiian Ridge reported by Rudnick et al. (2003); however, their measured diffusivity was $3 \times$ $10^{-4} \mathrm{~m}^{2} \mathrm{~s}^{-1}$ across the ridge, about two orders smaller than that in our study. It is reasonable to ask what kind of energy source could support such elevated turbulent mixing in the central SCS. Zhao (2014) examined the internal tide behavior in the SCS based on multiple satellite observations. His results suggested that $\mathrm{K}_{1}$ and $\mathrm{O}_{1}$ internal tides generated in the Luzon Strait could propagate to the Zhongsha Island Chain area (one of the high mixing areas in our study) along the central SCS deep basin, but their magnitudes in the central SCS are clearly weaker than those near the generation site. The $\mathrm{M}_{2}$ internal tides propagate over a shorter distance compared to the diurnal tides and are hardly detected in the Zhongsha Island Chain area. As a result, the total 


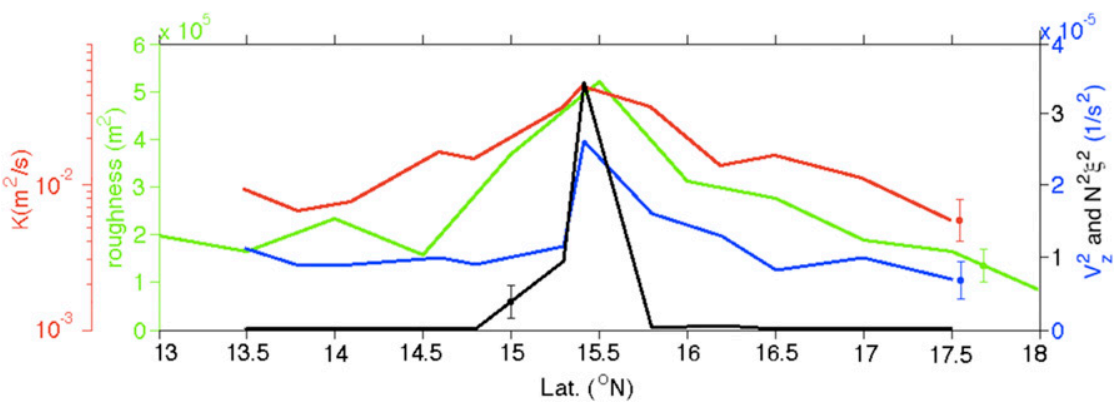

FIG. 14. Meridional distributions of zonally averaged diffusivity $\left(\mathrm{red} ; \mathrm{m}^{2} \mathrm{~s}^{-1}\right)$, shear variance (blue; $1 \mathrm{~s}^{-2}$ ), bathymetry roughness (green; $\mathrm{m}^{2}$ ), and squared buoyancy frequency times strain variance (black; $1 \mathrm{~s}^{-2}$ ) in the near-bottom layer (500 $\mathrm{m}$ above the bottom). Error bars indicate the uncertainty of standard deviation.

internal tide energy flux in the Zhongsha Island Chain area is significantly weaker than that near the Luzon Strait. The diffusivity values in these two areas, however, are comparable in magnitude. One likely explanation is that the internal tides generated in the Zhongsha Island Chain area are dissipated locally.

Let us take two boxes, which represent the Luzon Strait and Zhongsha Island Chain area, respectively, to analyze their bathymetries and barotropic tides (Fig. 15a). Slope spectra are computed along zonal and meridional directions in the Luzon Strait and Zhongsha Island Chain area, respectively, since the major axes of the tidal ellipse are almost in the zonal and meridional directions in these two areas (Figs. 15b,c). The slope spectra in these two regions are distinctly different. In the Luzon Strait, the mean slope spectrum has a high level at small wavenumbers $\left(<1 \times 10^{-4} \mathrm{rad} \mathrm{m}^{-1}\right)$. In contrast, the mean slope spectrum in the Zhongsha Island Chain area peaks around the wavenumber of $2 \times$ $10^{-4} \mathrm{rad} \mathrm{m}^{-1}$ and tapers off at lower and higher wavenumbers. This implies the internal tides with low vertical modes prevail in the Luzon Strait, which is supported by field measurements (e.g., Alford et al. 2011) and numerical simulations (e.g., Jan et al. 2008). In the Zhongsha Island Chain area, however, the internal tides with high vertical modes would prevail. Here, the equivalent mode number is toward the diurnal internal tide, which is determined by the modal dispersion relation given by $k_{j}=[(j \pi) / H]\left[\left(\omega^{2}-f^{2}\right) /\left(\bar{N}^{2}-\omega^{2}\right)\right]^{1 / 2}$, where $j$ is the mode number; $k_{j}$ is the corresponding horizontal wavenumber; $H$ and $f$ are the mean water depth and Coriolis frequency in the selected region, respectively; and $\omega$ is the diurnal frequency. The equivalent mode numbers for the diurnal tide are indicated at the top of Figs. 15b and 15c. The buoyancy frequency used is the averaged value from our measurements. We also examined the barotropic tidal information from the Oregon State University Tidal Data
Inversion (Egbert and Ray 2003; http://volkov.oce.orst. edu/tides/). The results show that the diurnal tides prevail in the Zhongsha Island Chain area, and the major axes are a quarter to a third of their counterparts in the Luzon Strait (Fig. 15d). However, the generated internal tides available for local turbulent dissipation are possibly comparable in these two areas, since part of the generated lower-mode internal tides in the Luzon Strait radiates away and enters the northern SCS (Niwa and Hibiya 2004); therefore, this part does not contribute crucially to the local mixing in the Luzon Strait. In contrast, most higher-mode internal tides generated in the Zhongsha Island Chain area are likely dissipated locally to furnish mixing. Clearly, this inference needs to be confirmed when time series observations over a longer period in the Zhongsha Island Chain area become available.

\section{d. Vertical velocity}

Based on the diffusivity results inferred from the GHP parameterization, vertical velocity $w_{\varepsilon}$ can be obtained from a vertical advective-diffusive balance model (Munk 1966; Munk and Wunsch 1998). This model is expressed as $w_{\varepsilon}(\partial \rho / \partial z)=\partial / \partial z[K(\partial \rho / \partial z)]$, and we used its incarnation of $w_{\varepsilon}=\left(0.2 / N^{2}\right)(\partial \varepsilon / \partial z)$. Here, the cubic fits to logarithmic stratification and dissipation rate profiles are used to calculate $w_{\varepsilon}$. First, the averaged dissipation and buoyancy frequency profiles yield one vertical velocity profile on the same grid as diffusivity shown in Fig. 6. Then, $w_{\varepsilon}$ at a specific depth is obtained by averaging all the vertical velocity values at that depth over the whole SCS. The errors of derived $w_{\varepsilon}$ are given by the uncertainty of standard deviation. Note that this velocity does not take into account any upward flows driven by wind stress curl and others, only those resulting from turbulent mixing. A persistent upwelling exists in the deep water of the SCS, which exceeds $30 \mathrm{~cm} \mathrm{day}^{-1}$ below $2700 \mathrm{~m}$, and becomes weaker at shallower depth 

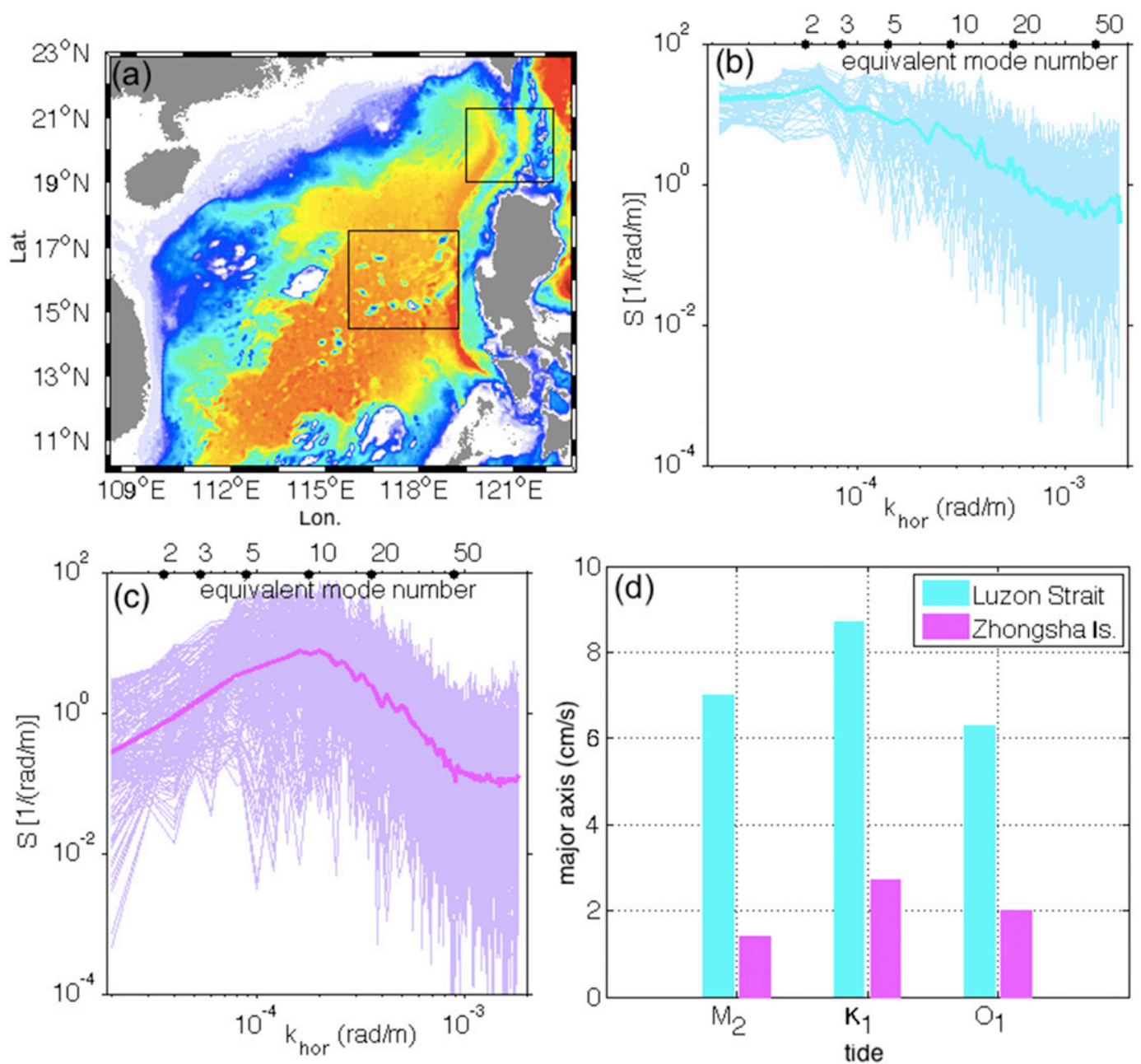

FIG. 15. (a) Bathymetry for the SCS and the two boxes representing the Luzon Strait and the Zhongsha Island Chain. (b),(c) The slope spectra in the two boxes, where the thin pink and cyan curves indicate individual slope spectra for the Luzon Strait and Zhongsha Island Chain area, respectively; the thick curves are their averages. (d) The major axis of barotropic tides $\mathrm{M}_{2}, \mathrm{~K}_{1}$, and $\mathrm{O}_{1}$ in the Luzon Strait (cyan) and Zhongsha Island Chain (pink). Here, the tidal information used is from the Oregon State University Tidal Data Inversion (http://volkov.oce.orst.edu/tides/), following Egbert and Ray (2003).

(Fig. 16). Maximum diapycnal upwelling of $46 \mathrm{~cm} \mathrm{day}^{-1}$ is found around $3300 \mathrm{~m}$. This upwelling is consistent with the deep-water exchange in the SCS reported by Tian et al. (2006) and Zhou et al. (2014) based on observations. These two studies noted the deep water of the SCS comes from the Pacific via the Luzon Strait due to density difference and moves upward by the heightened mixing in the deep SCS.

We also obtained the vertical motion $w_{\text {ECCO }}$ from a dynamically and kinematically consistent ocean state estimate system [Estimating the Circulation and Climate of the Ocean (ECCO) version 4, release 1; available at http://www.ecco-group.org/index.htm]. The ECCO product is the result of least squares fitting the Massachusetts Institute of Technology General
Circulation Model (MITgcm; Marshall et al. 1997) to a huge collection of global-scale observations (about $2 \times$ $10^{9}$ observational points). The vertical velocity is an output in the ECCO product, so we directly average it in the same way as we treated the balance model inferred $w_{\varepsilon}$ and compare the two. The vertical profile of $w_{\mathrm{ECCO}}$ shares a similar trend as that of $w_{\varepsilon}$, and their discrepancies are generally less than $10 \mathrm{~cm} \mathrm{day}^{-1}$. On average, the upwelling speeds in the SCS deep water are $32 \pm$ $5 \mathrm{~cm} \mathrm{day}^{-1}$ and $28 \mathrm{~cm} \mathrm{day}^{-1}$ based on $w_{\varepsilon}$ and $w_{\text {ECCO, }}$ respectively. Tian et al. (2006) and Yang et al. (2010) measured the Luzon Strait transport and found the Pacific water consistently entering the SCS below $1500 \mathrm{~m}$, with a transport $Q$ of $2.0 \mathrm{~Sv}$. Let $A$ be the area of the SCS at $1500 \mathrm{~m}$, which is estimated to be $8.3 \times 10^{11} \mathrm{~m}^{2}$. An 


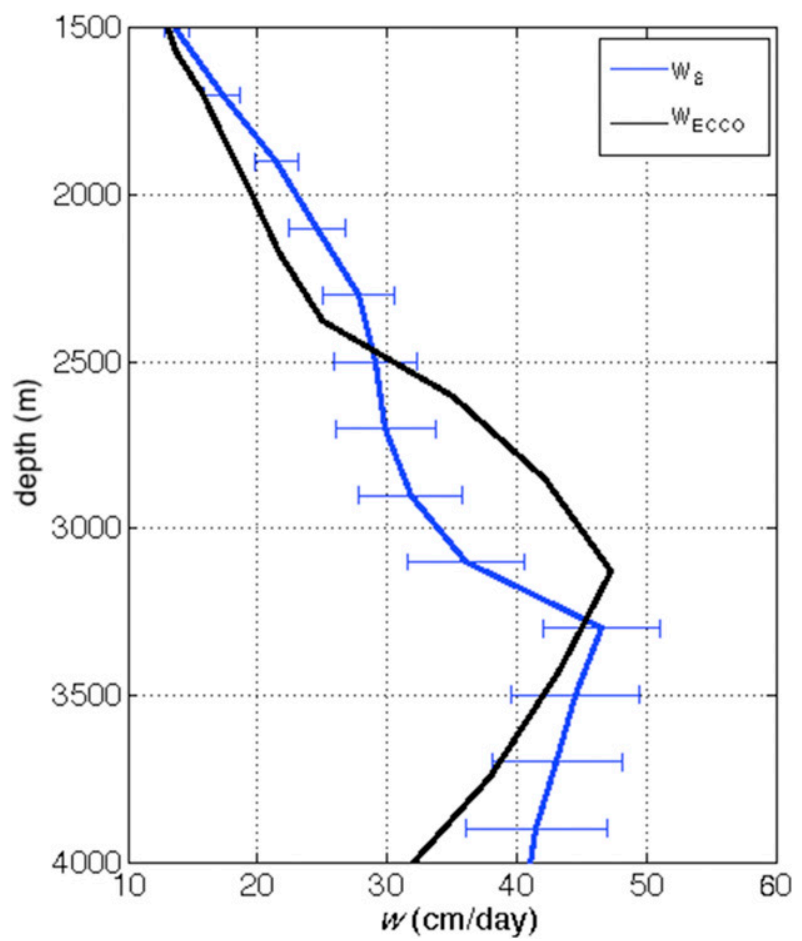

FIG. 16. Vertical velocity profiles in the deep water of the SCS. The blue curve (with error bars superimposed) is derived from the vertical advective-diffusive balance model based on GHP scaling inferred diffusivity, and the black curve is from the ECCO product (available at http://www.ecco-group.org/index.htm).

estimate of the average upwelling velocity of the deep water in the SCS can then be made using $w=Q / A=$ $21 \mathrm{~cm} \mathrm{day}^{-1}$. Qu et al. (2006) applied a hydraulic theory to estimate $Q$ and gave a rough estimate of upwelling speed at $24 \mathrm{~cm}_{\text {day }}{ }^{-1}$. These estimates are all comparable, which suggests that the deep water in the SCS moves upward much faster than the deep water in the open ocean (on the order of $0.1 \mathrm{~cm} \mathrm{day}^{-1}$; e.g., Kunze et al. 2006) due to enhanced mixing in the deep SCS.

\section{e. Summary}

The turbulent mixing in the SCS was examined based on the GHP finescale parameterization, and a
3D structure of diapycnal diffusivity was obtained for the first time. The results suggest that the mixing level in the SCS generally increases with depth, reaching the order of $10^{-2} \mathrm{~m}^{2} \mathrm{~s}^{-1}$ at depth. On average, the turbulence in the SCS becomes more active from south to north and from west to the east. In addition, two mixing "hotspots" were identified in the bottom water in the Luzon Strait and the Zhongsha Island Chain area, where diapycnal diffusivity is around $3 \times 10^{-2} \mathrm{~m}^{2} \mathrm{~s}^{-1}$. Potential mechanisms responsible for these spatial patterns were discussed, such as internal tides, bottom bathymetry, and near-inertial energy.

Using the hydrographic measurements over $8 \mathrm{yr}$, the spatial structure of the diffusivity in the SCS was investigated. Note that the results presented here did not take into account temporal variability at both seasonal and annual time scales. This may bias these spatial patterns. Fortunately, the results at most grids were obtained by averaging several observations from different cruises, which may reduce this bias. Moreover, the GHP parameterization may induce errors to the inferred diffusivity values, since the parameterization may not be completely appropriate for the SCS due to its potential limitations (Polzin et al. 2014). For example, Klymak et al. (2008) reported that the diffusivity predicted by the parameterization was smaller than that directly observed near the topography. We are, however, confident that the order of magnitude of the estimates and the 3D spatial pattern of turbulent mixing in the SCS reported here are robust and reliable, as the diffusivity results were confirmed by other independent methods (sections $2 \mathrm{~b}$ and $3 \mathrm{~b}$; Fig. S1 in the online supplemental information). We hope the mixing patterns unveiled in this study will be helpful for improving mixing configuration in the numerical model used for simulating a realistic ocean state in the SCS. Research on temporal variability of turbulent mixing in the SCS needs to be carried out when more data become available.

Acknowledgments. This work is supported by the National Key Basic Research Program of China (Grant

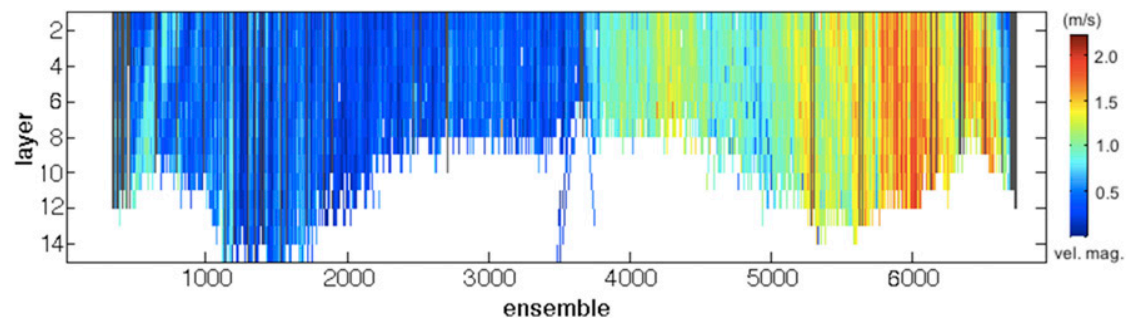

FIG. A1. Magnitude of relative velocity measured by the LADCP. The white area indicates no data, and the dark gray between colors indicates the discarded data after quality control. 


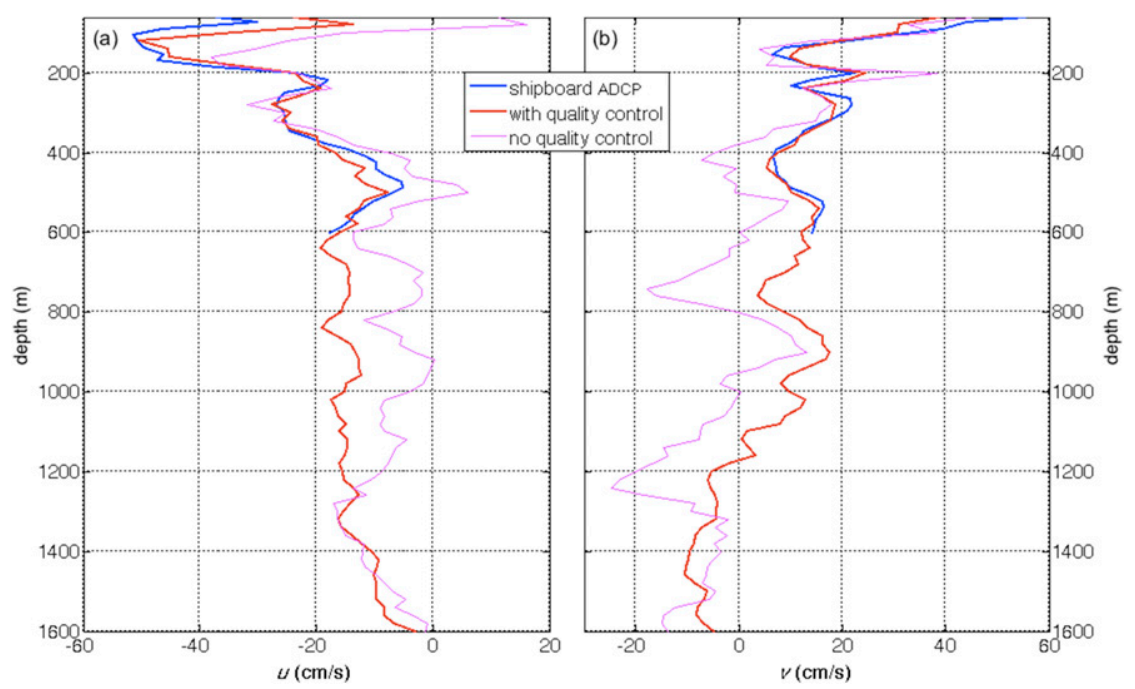

FIG. A2. (a) Zonal $u$ and (b) meridional $v$ components of absolute velocity. The blue curves are the velocity measurements from shipboard ADCP, which is WorkHorse Long Ranger $75 \mathrm{kHz}$ manufactured by Teledyne RD Instruments. The red and magenta curves are the derived velocity profiles from LADCP with and without quality control, respectively.

2014CB745003), the Natural Science Foundation of China (Grant 41576009), the NSFC-Shandong Joint Fund for Marine Science Research Centers (Grant U1406401), the Foundation for Innovative Research Groups of the National Natural Science Foundation of China (Grant 41521091), GASI-03-01-01-03, GASI-IPOVAI-01-03, the National High Technology Research and Development Program of China (Grants 2013AA09A501 and 2013AA09A502), and the Strategic Priority Research Program of the Chinese Academy of Sciences (Grant XDA11010202).

\section{APPENDIX A}

\section{Velocity Derived from LADCP Observations}

The LADCP used in the field experiment is WorkHorse Sentinel, manufactured by Teledyne RD Instruments. Its transducer frequency is $300 \mathrm{kHz}$. The datasheet of Teledyne RD Instruments states that the velocity accuracy is " $0.5 \%$ of the water velocity relative to ADCP $\pm 0.5 \mathrm{~cm} \mathrm{~s}^{-1}$." However, this uncertainty is for the relative water velocity with respect to the ADCP itself, not the absolute water velocity with respect to a fixed point on Earth. The uncertainty of absolute velocity is difficult to estimate accurately due to many factors, such as tilt, tilt difference, and processing method, among others (Firing 1998; Visbeck 2002). Both Firing (1998) and King et al. (2001) reported that the accuracy was a few centimeters per second except when backscattering was very low. A value of $\sim 3 \mathrm{~cm} \mathrm{~s}^{-1}$ was given for the accuracy by Thurnherr (2010). Our diffusivity results, however, are not sensitive to the accuracy of absolute velocity, since the shear involved in the diffusivity calculation can be obtained from the relative velocity profile, which has a higher accuracy.

The method we used to process the LADCP data is the inverse method. The software is from Andreas M. Thurnherr's release, version IX_10. Some key parameters we used to conduct data quality control when using this software are given below. First, we discarded the data when the tilt and the tilt difference between the adjacent pings exceed $22^{\circ}$ and $4^{\circ}$, respectively. Second, the limits of LADCP internal error velocity, horizontal velocity, and the vertical velocity deviation from the median of all bins in each ensemble were set to $0.5,2.5$, and $0.2 \mathrm{~m} \mathrm{~s}^{-1}$, respectively. The LADCP measurement was discarded if any of these limits were not met. Finally, side-lobe contaminated data near seabed and surface were not used in the calculation. As an example, one measurement is shown in Fig. A1; there are 6400 effective ensembles in all, and 1011 of them are discarded after quality control. Figure A2 shows the final velocity profile and the comparison with shipboard ADCP in the upper $600 \mathrm{~m}$. The results suggest that the velocity profiles after quality control are more consistent with the shipboard ADCP observation than before quality control. For most of a water column (300-1300 m), biases exist between the two velocity profiles, but these biases 

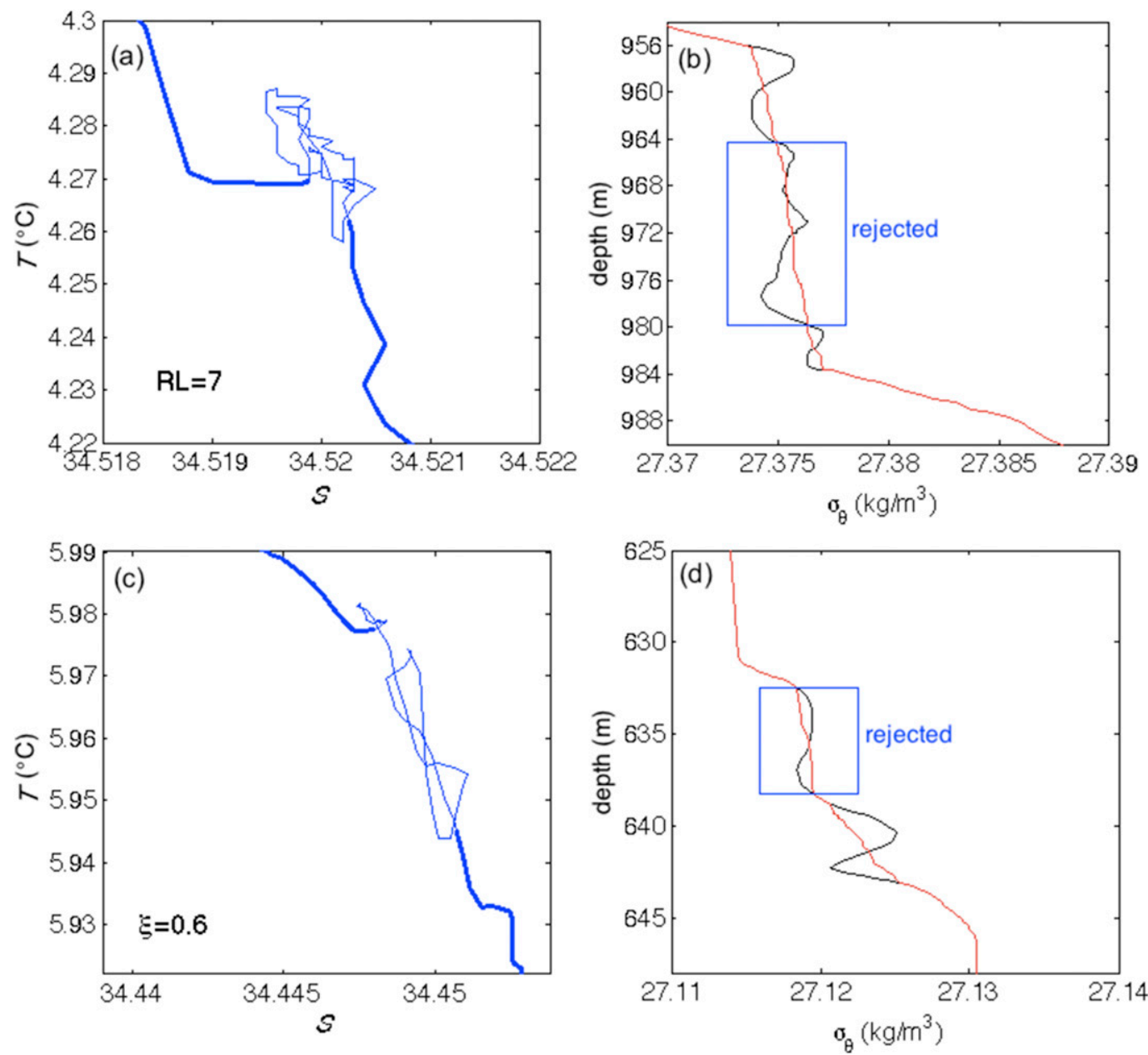

FIG. B1. Examples of the (top) run length test and (bottom) water mass test. (left) $T-S$ diagrams are shown, with the thin curves indicating failed tests. (right) The corresponding potential density profiles and the rejected overturns based on the tests are shown, where the black and red curves are original and sorted potential density profiles, respectively.

do not affect the shear significantly since they change little with depth.

\section{APPENDIX B}

\section{Diffusivity Estimation from CTD Observations}

The essence of diffusivity estimation from CTD measurements is to search for a reliable depth inversion from the original and sorted density profiles. One needs to first remove spurious pressure fluctuations in the CTD record due to cable shaking or ship movement. To remove these spikes, especially those in salinity, we did time averaging for the observed temperature and salinity. The CTD systems we used are SBE 911plus, SBE 917plus, and SBE 25, manufactured by Sea-Bird Electronics. SBE 911/917plus have a sampling rate of $24 \mathrm{~Hz}$, and SBE 25 has a sampling rate of $8 \mathrm{~Hz}$. As a result, we constructed a temporal average of $0.25 \mathrm{~s}$ for the measurements from SBE 911/917 and of $0.5 \mathrm{~s}$ for the measurements from SBE 25. The normal descending velocity of CTD is about $1 \mathrm{~m} \mathrm{~s}^{-1}$, which implies that the vertical resolution of the averaged record is about $0.25 \mathrm{~m}$ for SBE $911 / 917$ and about $0.5 \mathrm{~m}$ for SBE 25.

An overturn can be found by comparing the original density profile (with depth $z_{o}$ ) and the sorted one (with depth of $z_{s}$ ). The associated Thorpe scale is calculated based on the difference between $z_{o}$ and $z_{s}$ using $L_{T}=\sqrt{\overline{\left(z_{o}-z_{s}\right)^{2}}}$. The next step is to remove spurious overturns using two tests, following Galbraith and Kelley (1996). The first is the run length test, which is useful in detecting spurious density inversion caused by random noises. To increase the sample size and hence to 


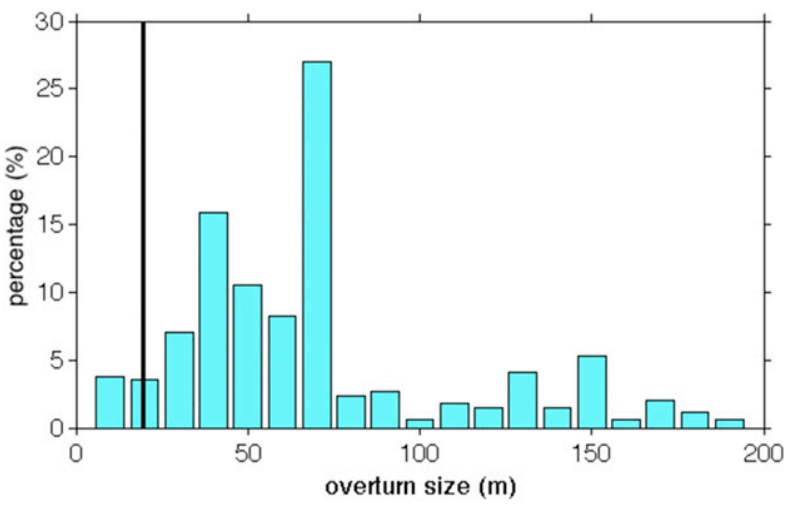

FIG. B2. Percentage of detected overturn size in the near-bottom layer of the Luzon Strait. The black vertical line indicates the upper limit of the minimum resolvable overturn size.

improve the accuracy of the cutoff of the run length in statistics, we conducted this test for all CTD casts used in this study. Here, the cutoff of the run length is set to seven. Besides the random noise, the systematic noise, such as that resulting from mismatches in time responses of temperature and conductivity probes, could cause density inversion, which is not a true mixing event (Galbraith and Kelley 1996). The second test, namely, the water mass test, was conducted to resolve this issue. A parameter $\xi$ was employed during the test, which is the maximum of nondimensional deviations of $\xi_{S}$ and $\xi_{T}$, where $\xi_{S}$ indicates the salinity-induced density deviation between observed and linearly fitted values, and $\xi_{T}$ is the temperature-induced density deviation. A critical value of $\xi=0.6$ is used in this study. Examples of these two tests are shown in Fig. B1.

A few factors, such as instrument accuracy level, local stratification, and vertical size of the overturn, could influence the accuracy of the Thorpe scale-derived diffusivity, as noted by Frants et al. (2013). They used the following approach to assess the reliability of the Thorpe-scale inferred diffusivity, that is, to examine the difference between the minimum resolvable overturn size and the dominated overturn size. The comparison performed in the near-bottom layer of the Luzon Strait is shown in Fig. B2, which suggests there was a significant difference of $50 \mathrm{~m}$, implying that the Thorpe scalederived diffusivity in our study is reliable.

\section{REFERENCES}

Alford, M. H., and R. Pinkel, 2000: Observations of overturning in the thermocline: The context of ocean mixing. J. Phys. Oceanogr., 30, 805-832, doi:10.1175/1520-0485(2000)030<0805: OOOITT $>2.0 . \mathrm{CO} ; 2$.

- R.-C. Lien, H. Simmons, J. Klymak, S. Ramp, Y. J. Yang, and M.-H. Chang, 2010: Speed and evolution of nonlinear internal waves transiting the South China Sea. J. Phys. Oceanogr., 40, 1338-1355, doi:10.1175/2010JPO4388.1.

_ Strait: Two tales of two ridges. J. Phys. Oceanogr., 41, 22112222, doi:10.1175/JPO-D-11-073.1.

- M. F. Cronin, and J. M. Klymak, 2012: Annual cycle and depth penetration of wind-generated near-inertial internal waves at Ocean Station Papa in the northeast Pacific. J. Phys. Oceanogr., 42, 889-909, doi:10.1175/JPO-D-11-092.1.

Buijsman, M. C., S. Legg, and J. Klymak, 2012: Double-ridge internal tide interference and its effect on dissipation in Luzon Strait. J. Phys. Oceanogr., 42, 1337-1356, doi:10.1175/JPO-D-11-0210.1.

Chaigneau, A., O. Pizarro, and W. Rojas, 2008: Global climatology of near-inertial current characteristics from Lagrangian observations. Geophys. Res. Lett., 35, L13603, doi:10.1029/ 2008GL034060.

Chang, M.-H., R.-C. Lien, T. Y. Tang, E. A. D'Asaro, and Y. J. Yang, 2006: Energy flux of nonlinear internal waves in northern South China Sea. Geophys. Res. Lett., 33, L03607, doi:10.1029/2005GL025196.

Dillon, T. M., 1982: Vertical overturns: A comparison of Thorpe and Ozmidov length scales. J. Geophys. Res., 87, 9601-9613, doi:10.1029/JC087iC12p09601.

Duda, T. F., J. F. Lynch, A. E. Newhall, L. Wu, and C.-S. Chiu, 2004: Fluctuation of $400-\mathrm{Hz}$ sound intensity in the 2001 ASIAEX South China Sea Experiment. IEEE J. Oceanic Eng., 29, 1264-1279, doi:10.1109/JOE.2004.836997.

Egbert, G. D., and R. D. Ray, 2003: Semi-diurnal and diurnal tidal dissipation from TOPEX/Poseidon altimetry. Geophys. Res. Lett., 30, 1907, doi:10.1029/2003GL017676.

Finnigan, T. D., D. S. Luther, and R. Lukas, 2002: Observations of enhanced diapycnal mixing near the Hawaiian Ridge. J. Phys. Oceanogr., 32, 2988-3002, doi:10.1175/1520-0485(2002)032<2988: OOEDMN $>2.0 . \mathrm{CO} ; 2$.

Firing, E., 1998: Lowered ADCP development and use in WOCE. International WOCE Newsletter, No. 30, WOCE International Project Office, Southampton, United Kingdom, 10-14.

Frants, M., G. M. Damerell, S. T. Gille, K. J. Heywood, J. MacKinnon, and J. Springtall, 2013: An assessment of density-based finescale methods for estimating diapycnal diffusivity in the Southern Ocean. J. Atmos. Oceanic Technol., 30, 2647-2661, doi:10.1175/JTECH-D-12-00241.1.

Galbraith, P. S., and D. E. Kelley, 1996: Identifying overturns in CTD profiles. J. Atmos. Oceanic Technol., 13, 688-702, doi:10.1175/1520-0426(1996)013<0688:IOICP>2.0.CO;2.

Garrett, C., and W. Munk, 1972: Space-time scales of internal waves. Geophys. Fluid Dyn., 3, 225-264, doi:10.1080/ 03091927208236082.

— progress report. J. Geophys. Res., 80, 291-297, doi:10.1029/ JC080i003p00291.

Gregg, M. C., T. B. Sanford, and D. P. Winkel, 2003: Reduced mixing from the breaking of internal waves in equatorial ocean waters. Nature, 422, 513-515, doi:10.1038/nature01507.

Jan, S., C.-S. Chern, J. Wang, and S.-Y. Chao, 2007: Generation of diurnal $\mathrm{K}_{1}$ internal tide in the Luzon Strait and its influence on surface tide in the South China Sea. J. Geophys. Res., 112, C06019, doi:10.1029/2006JC004003.

— R.-C. Lien, and C.-H. Ting, 2008: Numerical study of baroclinic tides in Luzon Strait. J. Oceanogr., 64, 789-802, doi:10.1007/s10872-008-0066-5.

King, B. A., E. Firing, and T. M. Joyce, 2001: Shipboard observations during WOCE. Ocean Circulation and Climate: 
Observing and Modelling the Global Ocean, G. Siedler, J. Church, and J. Gould, Eds., Academic Press, 99-122.

Klymak, J. M., R. Pinkel, C.-T. Liu, A. K. Liu, and L. David, 2006: Prototypical solitons in the South China Sea. Geophys. Res. Lett., 33, L11607, doi:10.1029/2006GL025932.

- - - and L. Rainville, 2008: Direct breaking of the internal tide near topography: Kaena Ridge, Hawaii. J. Phys. Oceanogr., 38, 380-399, doi:10.1175/2007JPO3728.1.

- M. H. Alford, R. Pinkel, R.-C. Lien, Y. J. Yang, and T.-Y. Tang, 2011: The breaking and scattering of the internal tide on a continental slope. J. Phys. Oceanogr., 41, 926-945, doi:10.1175/2010JPO4500.1.

Kunze, E., E. Firing, J. M. Hummon, T. K. Chereskin, and A. M. Thurnherr, 2006: Global abyssal mixing inferred from lowered ADCP shear and CTD strain profiles. J. Phys. Oceanogr., 36, 1553-1576, doi:10.1175/JPO2926.1.

Levine, M. D., and T. J. Boyd, 2006: Tidally forced internal waves and overturns observed on a slope: Results from the HOME. J. Phys. Oceanogr., 36, 1184-1201, doi:10.1175/JPO2887.1.

Lien, R.-C., T. Y. Tang, M. H. Chang, and E. A. D'Asaro, 2005: Energy of nonlinear internal waves in the South China Sea. Geophys. Res. Lett., 32, L05615, doi:10.1029/2004GL022012.

—, F. Henyey, B. Ma, and Y. J. Yang, 2014: Large-amplitude internal solitary waves observed in the northern South China Sea: Properties and energetics. J. Phys. Oceanogr., 44, 10951115, doi:10.1175/JPO-D-13-088.1.

Lozovatsky, I., Z. Liu, H. J. S. Fernando, J. Hu, and H. Wei, 2013: The TKE dissipation rate in the northern South China Sea. Ocean Dyn., 63, 1189-1201, doi:10.1007/s10236-013-0656-7.

Marshall, J., A. Adcroft, C. Hill, L. Perelman, and C. Heisey, 1997: A finite-volume, incompressible Navier Stokes model for studies of the ocean on parallel computers. J. Geophys. Res., 102, 5753-5766, doi:10.1029/96JC02775.

Munk, W., 1966: Abyssal recipes. Deep-Sea Res. Oceanogr. Abstr., 13, 707-730, doi:10.1016/0011-7471(66)90602-4.

_, and C. Wunsch, 1998: Abyssal recipes II: Energetics of tidal and wind mixing. Deep-Sea Res., 45, 1977-2010, doi:10.1016/ S0967-0637(98)00070-3.

Naveira Garabato, A. C., K. L. Polzin, B. A. King, K. J. Heywood, and M. Visbeck, 2004: Widespread intense turbulent mixing in the Southern Ocean. Science, 303, 210-213, doi:10.1126/ science.1090929.

Niwa, Y., and T. Hibiya, 2004: Three-dimensional numerical simulation of $\mathrm{M}_{2}$ internal tides in the East China Sea. J. Geophys. Res., 109, C04027, doi:10.1029/2003JC001923.

Osborn, T. R., 1980: Estimates of the local rate of vertical diffusion from dissipation measurements. J. Phys. Oceanogr., 10, 83-89, doi:10.1175/1520-0485(1980)010<0083:EOTLRO > 2.0.CO;2.

Pinkel, R., 2000: Internal solitary wave in the warm pool of the western equatorial Pacific. J. Phys. Oceanogr., 30, 2906-2926, doi:10.1175/1520-0485(2001)031<2906:ISWITW>2.0.CO;2.

Polzin, K. L., E. Kunze, J. Hummon, and E. Firing, 2002: The finescale response of lowered ADCP velocity profiles. J. Atmos. Oceanic Technol., 19, 205-224, doi:10.1175/ 1520-0426(2002)019<0205:TFROLA > 2.0.CO;2.

, A. C. N. Garabato, T. N. Huussen, B. M. Sloyan, and S. Waterman, 2014: Finescale parameterizations of turbulent dissipation. J. Geophys. Res. Oceans, 119, 1383-1419, doi:10.1002/2013JC008979.
Qu, T., J. B. Girton, and J. A. Whitehead, 2006: Deepwater overflow through Luzon Strait. J. Geophys. Res., 111, C01002, doi:10.1029/2005JC003139.

Ramp, S. R., and Coauthors, 2004: Internal solitons in the northeastern South China Sea. Part I: Sources and deep water propagation. IEEE J. Oceanic Eng., 29, 1157-1181, doi:10.1109/ JOE.2004.840839.

Rudnick, D. L., and Coauthors, 2003: From tides to mixing along the Hawaiian Ridge. Science, 301, 355-357, doi:10.1126/ science.1085837.

Smith, W., and D. Sandwell, 1997: Global sea floor topography from satellite altimetry and ship depth soundings. Science, 277, 1956-1962, doi:10.1126/science.277.5334.1956.

St. Laurent, L. C., 2008: Turbulent dissipation on the margins of the South China Sea. Geophys. Res. Lett., 35, L23615, doi:10.1029/ 2008GL035520.

- - and C. Garrett, 2002: The role of internal tides in mixing the deep ocean. J. Phys. Oceanogr., 32, 2882-2899, doi:10.1175/ 1520-0485(2002)032<2882:TROITI >2.0.CO;2.

Thurnherr, A. M., 2010: A practical assessment of the errors associated with full-depth LADCP profiles obtained using Teledyne RDI workhorse acoustic Doppler current profilers. J. Atmos. Oceanic Technol., 27, 1215-1227, doi:10.1175/ 2010JTECHO708.1.

— 2012: The finescale response of lowered ADCP velocity measurements processed with different methods. J. Atmos. Oceanic Technol., 29, 597-600, doi:10.1175/JTECH-D-11-00158.1.

Tian, J., Q. Yang, X. Liang, L. Xie, D. Hu, F. Wang, and T. Qu, 2006: Observation of Luzon Strait transport. Geophys. Res. Lett., 33, L19607, doi:10.1029/2006GL026272.

— _ _ a and W. Zhao, 2009: Enhanced diapycnal mixing in the South China Sea. J. Phys. Oceanogr., 39, 3191-3203, doi:10.1175/2009JPO3899.1.

Visbeck, M., 2002: Deep velocity profiling using lowered acoustic Doppler current profilers: Bottom track and inverse solutions. J. Atmos. Oceanic Technol., 19, 794-807, doi:10.1175/1520-0426(2002)019<0794:DVPULA>2.0.CO;2.

Waterman, S., A. C. Naveira-Garabato, and K. Polzin, 2013: Internal waves and turbulence in the Antarctic Circumpolar Current. J. Phys. Oceanogr., 43, 259-282, doi:10.1175/JPO-D-11-0194.1.

Xu, J., J. Xie, Z. Chen, S. Cai, and X. Long, 2012: Enhanced mixing induced by internal solitary waves in the South China Sea. Cont. Shelf Res., 49, 34-43, doi:10.1016/j.csr.2012.09.010.

Yang, Q., J. Tian, and W. Zhao, 2010: Observation of Luzon Strait transport in summer 2007. Deep-Sea Res. I, 57, 670-676, doi:10.1016/j.dsr.2010.02.004.

,,,--- X. Liang, and L. Zhou, 2014: Observations of turbulence on the shelf and slope of northern South China Sea. Deep-Sea Res. I, 87, 43-52, doi:10.1016/j.dsr.2014.02.006.

Zhao, Z., 2014: Internal tide radiation from the Luzon Strait. J. Geophys. Res. Oceans, 119, 5434-5448, doi:10.1002/ 2014JC010014.

_ - V. Klemas, Q. Zheng, and X.-H. Yan, 2004: Remote sensing evidence for baroclinic tide origin of internal solitary waves in the northeastern South China Sea. Geophys. Res. Lett., 31, L06302, doi:10.1029/2003GL019077.

Zhou, C., W. Zhao, J. Tian, Q. Yang, and T. Qu, 2014: Variability of the deep water overflow in the Luzon Strait. J. Phys. Oceanogr., 44, 2972-2986, doi:10.1175/JPO-D-14-0113.1. 